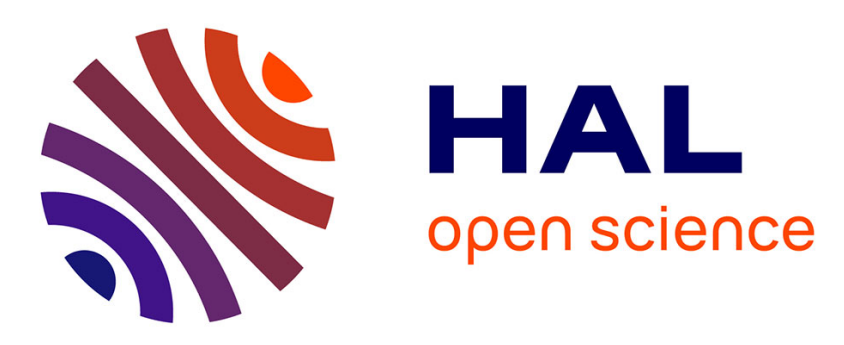

\title{
Friction weakening in granular flows deduced from seismic records at the Soufrière Hills Volcano, Montserrat
}

Clara Lévy, Anne Mangeney, Fabian Bonilla, Clément Hibert, Eliza S Calder, Patrick J. Smith

\section{To cite this version:}

Clara Lévy, Anne Mangeney, Fabian Bonilla, Clément Hibert, Eliza S Calder, et al.. Friction weakening in granular flows deduced from seismic records at the Soufrière Hills Volcano, Montserrat. Journal of Geophysical Research : Solid Earth, 2015, 120 (11), pp.7536-7557. 10.1002/2015JB012151 . hal02453860

\section{HAL Id: hal-02453860 https://hal.science/hal-02453860}

Submitted on 21 Aug 2020

HAL is a multi-disciplinary open access archive for the deposit and dissemination of scientific research documents, whether they are published or not. The documents may come from teaching and research institutions in France or abroad, or from public or private research centers.
L'archive ouverte pluridisciplinaire HAL, est destinée au dépôt et à la diffusion de documents scientifiques de niveau recherche, publiés ou non, émanant des établissements d'enseignement et de recherche français ou étrangers, des laboratoires publics ou privés. 


\section{Journal of Geophysical Research: Solid Earth}

\section{RESEARCH ARTICLE \\ 10.1002/2015JB012151 \\ Friction weakening in granular flows deduced from seismic records at the Soufrière Hills Volcano, Montserrat}

Key Points:

- The friction weakening of granular

flows was evidenced using

seismic data

- Conversion of potential to seismic energy is almost constant for granular flows

- Seismic energy correlates with the force applied by granular flows to the ground

Correspondence to:

C. Levy,

c.levy@brgm.fr

\section{Citation:}

Levy, C., A. Mangeney, F. Bonilla, C. Hibert, E. S. Calder, and P. J. Smith (2015), Friction weakening in granular flows deduced from seismic records at the Soufrière Hills Volcano, Montserrat, J. Geophys. Res. Solid Earth, 120, 7536-7557, doi:10.1002/2015JB012151.

Received 22 APR 2015 Accepted 5 OCT 2015 Accepted article online 10 OCT 2015 Published online 6 NOV 2015

○2015. American Geophysical Union. All Rights Reserved.

\author{
Clara Levy ${ }^{1,2,3}$, Anne Mangeney ${ }^{1,4}$, Fabian Bonilla ${ }^{1,2}$, Clément Hibert ${ }^{1,3}$, Eliza S. Calder ${ }^{5}$, \\ and Patrick J. Smith ${ }^{6,7}$
}

${ }^{1}$ Institut de Physique du Globe de Paris, CNRS UMR 7154, Université Paris Diderot-Paris 7, Paris, France, ${ }^{2}$ IFSTTAR, Université Paris-Est, Paris, France, ${ }^{3}$ Bureau des Recherches Géologiques et Minières, Orleans, France, ${ }^{4}$ ANGE team, CEREMA, INRIA, Laboratoire Jacques-Louis Lions, Paris, France, ${ }^{5}$ School of GeoSciences, University of Edinburgh, Edinburgh, UK, ${ }^{6}$ Montserrat Volcano Observatory, Flemings, Montserrat, ${ }^{7}$ Seismic Research Centre, University of the West Indies, St. Augustine, Trinidad and Tobago

Abstract Accurate modeling of rockfalls and pyroclastic flows is still an open issue, partly due to a lack of measurements related to their dynamics. Using seismic data from the Soufrière Hills Volcano, Montserrat, and granular flow modeling, we show that the power laws relating the seismic energy $E_{s}$ to the seismic duration $t_{s}$ and relating the loss of potential energy $\Delta E_{p}$ to the flow duration $t_{f}$ are very similar, like the power laws observed at Piton de la Fournaise, Reunion Island. Observations showing that $t_{f} \simeq t_{s}$ suggest a constant ratio $E_{s} / \Delta E_{p} \simeq 10^{-5}$. This similarity in these two power laws can be obtained only when the granular flow model uses a friction coefficient that decreases with the volume transported. Furthermore, with this volume-dependent friction coefficient, the simulated force applied by the flow to the ground correlates well with the seismic energy, highlighting the signature of this friction weakening effect in seismic data.

\section{Introduction}

Volcanic activity often generates rockfalls and pyroclastic flows. The areas reached by these natural hazards as well as their dynamics remain difficult to predict because of the lack of precise measurements on the propagation phase. Yet as the mass accelerates and decelerates over the topography, it generates seismic waves due to the fluctuations of the basal stress applied to the ground. The emitted signal covers a large range of frequencies related to the mean friction and loading/unloading of the flowing mass and to the rebounds of the involved grains. Seismic monitoring has therefore been used increasingly over the years to collect valuable information on the flow dynamics at different scales [Hibert et al., 2014a; Moretti et al., 2015; Allstadt, 2013]. These data overcome the difficulty of making direct visual observations in the presence of clouds, darkness, or an incomplete view of the volcano.

However, deriving the characteristics of the gravitational flows from seismic properties is not straightforward because the generated seismic signal is a complex combination of the effects of volume, flow dynamics, interactions with the topography, wave propagation properties, etc., [Suriñach et al., 2005; Deparis et al., 2008; Hibert et al., 2011]. Low-frequency seismic signals have been inverted to find the seismic source mechanism and have been simulated using a combination of landslide and wave propagation models [Brodsky et al., 2003; Favreau et al., 2010; Moretti et al., 2012, 2015; Yamada et al., 2013]. High-frequency seismic signals are, however, very difficult to invert and simulate, as the Earth model at these frequencies and the associated Green's functions are usually unknown. As a result, these signals are mostly analyzed using empirical laws that attempt to relate the signal properties to the granular flow characteristics [Suriñach et al., 2005; Deparis et al., 2008; Helmstetter and Garambois, 2010; Lacroix and Helmstetter, 2011; Dammeier et al., 2011; Hibert et al., 2011, 2014b]. The challenge is to extract information on the rheological properties of the natural granular flows from these laws. Indeed, one of the main issues in understanding landslide dynamics is the apparent low friction acting during the downslope motion of large landslides [Heim, 1932; Dade and Huppert, 1998; Pouliquen, 1999; Legros, 2002; Lucas and Mangeney, 2007; Lucas et al., 2011, 2014]. Field observations show that large landslides travel over unexpectedly long distances when comparing to smaller landslides, suggesting lower dissipation during their flow than for smaller landslides. 
Lucas et al. [2014] have quantified this friction weakening effect on the basis of observations of runout distances (i.e., static measurements) of a wide range of small to large landslides. We address here the question as to whether the signature of this friction weakening can be identified in seismic data, i.e., in data related to the flow dynamics.

Since the 1990s, many studies have attempted to relate the characteristics of seismic signals (amplitude, energy, and duration) to rockfall properties (volume, duration, and path [Norris, 1994; Brodsky et al., 2003; Suriñach et al., 2005; Vilajosana et al., 2008; Deparis et al., 2008; Helmstetter and Garambois, 2010; Lacroix and Helmstetter, 2011; Dammeier et al., 2011; Hibert et al., 2011]). In particular, using seismic and photogrammetric data from rockfalls at Piton de la Fournaise volcano (Reunion Island), Hibert et al. [2011] showed that the power law relating the seismic energy $E_{s}$ to the seismic duration $t_{s}$

$$
E_{s} \propto t_{s}^{\beta}
$$

where $\beta$ is a constant and is similar to the power law relating the loss of potential energy $\Delta E_{p}$ of the granular mass to the flow duration $t_{f}$

$$
\Delta E_{p} \propto t_{f}^{\beta}
$$

In the following sections, we annotate $\beta_{p}$ or $\beta_{s}$ this power law coefficient in order to distinguish when it is estimated using loss of potential energy values or seismic energy values.

As field observations have shown that $t_{s} \approx t_{f}$, this similarity in the power laws has been used to determine a value between $10^{-5}$ and $10^{-3}$ for the mean ratio of seismic to potential energy $R_{s / p}=E_{s} / \Delta E_{p}$ [Hibert et al., 2011, 2014b], in agreement with Deparis et al. [2008] for rockfalls in the French Alps. The similarity in power laws (1) and (2) makes it possible to calculate the volume of the granular flow from the measured seismic energy. Numerical simulations have shown that the coefficient $\beta$ of the observed power law is highly sensitive to the interaction of the granular flow with the underlying topography [Hibert et al., 2011].

An important question is whether or not power laws (1) and (2) and their similarity are also observed in contexts other than those of the Piton de la Fournaise volcano. In particular, major simplifications were made in the seismic energy calculation, potentially affecting the quantification of the parameters involved in the power law and thus the volume calculation. Indeed, the attenuation was not considered frequency dependent and only vertical component seismometers were used in Hibert et al. [2011]. Furthermore, because rockfalls at Piton de la Fournaise only involve relatively small volumes (up to thousands of cubic meters), the potential friction weakening occurring during large volume landslides has not been identified.

By combining seismic data and granular flow modeling, our aims are (i) to show that these power laws and energy ratios are universal and can be observed in other geological contexts and (ii) to provide evidence for and quantify the friction weakening effect of granular flows involving large volumes from data related to the flow dynamics.

More specifically, these aims are as follows:

1. Using 200 records of granular flows at the Soufrière Hills Volcano (Montserrat Island), we demonstrate that a power law (1) similar to the one obtained by Hibert et al. [2011] is observed. We also find that the parameters of this power law depend on the valley in which the granular flows occur.

2. By considering frequency-dependent parameters and all the components of the ground velocity, we improve the calculation of the seismic energy and show that the coefficients of power law (1) are very stable, supporting its relevance.

3. Using numerical simulations of granular flows at the Soufrière Hills Volcano, we show that power law (2) also holds at this site. Interestingly, the power law deduced from seismic data can only be reproduced by simulations with a friction coefficient that decreases with the volume [Lucas et al., 2014] and not with a constant friction coefficient. The good agreement between simulations and seismic observations shows that friction weakening is not negligible in the dynamics of large volumes.

4. Finally, we show that the scatter of the power law coefficients constrained by seismic data is essentially due to topographic effects, which strikingly influence the mass propagation. We show that pulses in the seismic envelope are directly related to the interaction of the flow with the topography changes. 


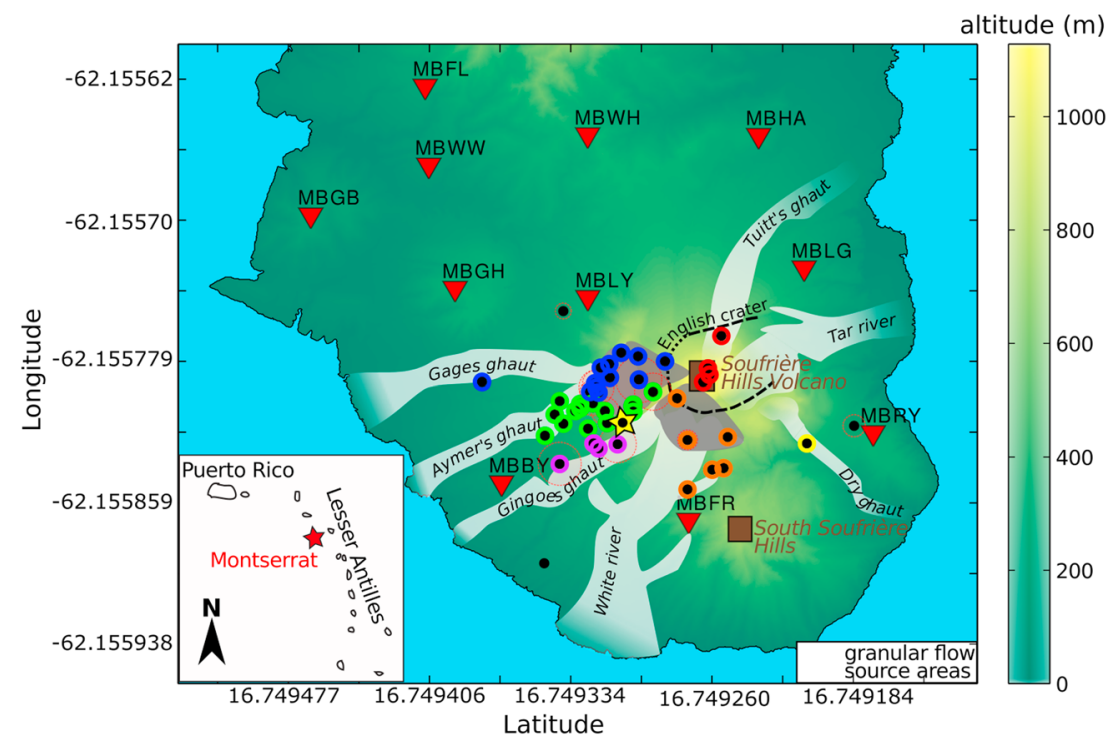

Figure 1. Epicenters of the 46 granular flows that could be located from records from 4 to 6 November 2009 on the Soufrière Hills Volcano.Main figure: Epicenters of the granular flows that could be located. Estimations of the location errors are represented by red circles. Events located within the valleys are circled in color: blue for Gages ghaut, green for Aymer's ghaut, purple for Gingoes ghaut, orange for White River, yellow for Dry ghaut, and red for Tuitt's ghaut. The event presented in Figure 3 is indicated by a star on the border of Aymer's ghaut. The volcanic centers of the southern part of Montserrat are represented by brown squares. The MVO seismic stations used in this study are represented as red triangles. Insert: Location of Montserrat within the Lesser Antilles arc.

\section{Characteristics and Location of Rockfalls and Pyroclastic Flows}

\subsection{Geological Context at the Soufrière Hills Volcano}

Montserrat Island is located in the Lesser Antilles arc (insert of Figure 1) where the Atlantic plate is being subducted beneath the Caribbean plate [Feuillet et al., 2002]. This island comprises four volcanic centers with ages ranging from 2.5 Ma to the present [Harford et al., 2002; Le Friant et al., 2008]. The latest center in activity is the Soufrière Hills Volcano, which dominates the southern two thirds of the island at about $1 \mathrm{~km}$ above sea level. Its activity started at least 170 ka ago [Sparks and Young, 2002]. The upper structure of the Soufrière Hills Volcano is a set of andesitic domes surrounded by a cloak of pyroclastic deposits and collapse debris [Young et al., 1998].

After a long period of dormancy, Soufrière Hills Volcano became active in 1995 with a series of phreatic eruptions [Young et al., 1998]. Since 1995, the activity of this volcano has seen alternate phases of dome growth and collapses that have produced onshore and offshore pyroclastic and debris flow deposits [e.g., Deplus et al., 2001; Le Friant et al., 2004; Trofimovs et al., 2006; Le Friant et al., 2009; Loughlin et al., 2010]. For more details on the setting of the Soufrière Hills Volcano, see Kokelaar [2002].

\subsection{Rockfalls and Pyroclastic Flows at the Soufrière Hills Volcano}

We analyze the seismic signal of a series of 200 rockfalls and pyroclastic flows occurring during a 3 day crisis starting 4 November 2009. This period with important rockfalls and pyroclastic flows activity occurs during the fifth phase of lava extrusion (phase 5) that lasted from 9 October 2009 to 11 February 2010. The volumes of these granular flows are estimated to range between $10^{3}$ and $10^{6} \mathrm{~m}^{3}$ while their durations range from a few tens of seconds to about $350 \mathrm{~s}$ (E. Calder, University of Edinburgh, personal communication, 2013). Both types of events consist of a mixture of hot rock and ash. The difference lies on the size of the events, as the Montserrat Volcano Observatory (MVO) classifies the smaller ones as rockfalls and the larger ones as pyroclastic flows. Figure 2 presents photographs of two events occurring at the Soufrière Hills Volcano, one rockfall and one pyroclastic flow.

Most rockfalls and pyroclastic flows originate from the dome of the Soufrière Hills Volcano (grey areas in Figure 1) [Jolly et al., 2002]. Materials spread downward, roughly following preferential paths such as the surrounding valleys. Rockfalls rarely travel far beyond the base of the talus apron, 500-800 $\mathrm{m}$ from the dome summit, whereas the bigger events can propagate several kilometers and reach the sea shore. 


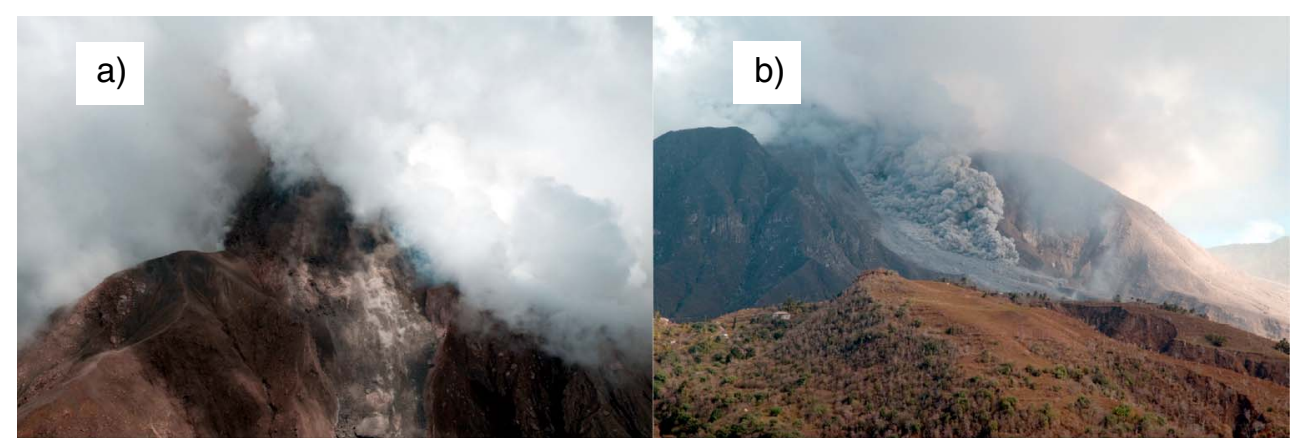

Figure 2. Photos of a rockfall and a pyroclastic flow at the Soufrière Hills Volcano.(a) Rockfall dust trail on the upper part of White River. (b) Pyroclastic flow going down Gages ghaut.

\subsection{Characteristics of the Seismic Events}

The seismic signals were recorded at nine digital stations belonging to the permanent seismic network of the MVO (Figure 1). The stations were equipped with Guralp CMG-40T $3 \mathrm{C}$ broadband sensors, having a bandwidth of $0.03-30 \mathrm{~Hz}$. The sampling rate was $100 \mathrm{~Hz}$. The events studied here have been identified by the MVO with the usual procedures applied at the Soufrière Hills Volcano, as described by Miller et al. [1998]. The main categories currently in use at MVO are VT (volcano-tectonic), hybrid, long period, and rockfalls (including both pyroclastic flows and rockfalls). There is no automatic classification at MVO and triggered events are manually classified by a seismic analyst, mainly on the basis of waveform and with additional spectral analysis if required.

Seismic signals associated with rockfalls are complex given that the source of the seismic waves propagates downslope, while covering an area of increasing size. Authors like Hibert et al. [2011] and Deparis et al. [2008] report observations that the duration of the seismic signal is about the same duration as the propagation of materials on the slope (i.e., the duration of the seismic source). An example of a typical recorded signal is given in Figure 3a. As in this example, these signals have emerging onsets and ragged wave train envelopes. Most of them are characterized by dominant frequencies $f$ between 2 and $10 \mathrm{~Hz}$ [Langer et al., 2006], although energy is found over the wider range $1<f<20 \mathrm{~Hz}$ (Figure $3 b$ ).

It is often assumed that rockfall signals are mainly made of surface waves [Rousseau, 1999; Deparis et al., 2008; Zhao et al., 2012]. However, as the source is very complex, it is difficult to identify wave packets within the data. Figures $3 c-3 e$ present the signal filtered at increasing frequency bands, together with the corresponding polarization plots (Figures $3 \mathrm{f}$ and $3 \mathrm{~g}$ ). The envelope of the signal at low frequency (Figure $3 \mathrm{c}$ ) is smooth and cigar shaped, and the wave packets are well mixed (see the polarization plots of Figure $3 \mathrm{f}$ ). When the recording station is close to the seismic source, the signal has impulsive parts at high frequency (see the signal in purple on the zoom of Figure $3 \mathrm{~d}$ ), and the corresponding wave arrivals can be identified (see the zoom on the polarization plots of Figure $3 \mathrm{~g}$ ). The elliptical motion identifies them as surface waves.

\subsection{Automatic Picking Using the Kurtosis of the Signal}

Seismic signals associated with rockfalls have emerging onsets. This particular feature makes the picking of arrival times with classical seismological methods impractical and unreliable.

A specific automated method based on kurtosis has been used here [Baillard et al., 2013; Hibert et al., 2014b]. This statistical method measures the fourth moment of the amplitude distribution of the signal. The principle is the following: kurtosis indicates the resemblance to a normal distribution. The amplitude distribution is normal for seismic noise and events but turns leptokurtic at the transition between noise and event (i.e., the amplitude distribution is sharper, or more peaked, than a normal distribution and the value of the kurtosis is greater than 3). Thus, by computing the value of the kurtosis for small sliding time windows, we can find the onset of rockfall signals, when the value of the kurtosis increases. This procedure is performed on the filtered seismic signal for sliding windows of varying sizes. The final picking takes into account the results for the signal filtered on multiple frequency bands. For our database, optimal parameters were sliding windows of $5 \mathrm{~s}$, $10 \mathrm{~s}$, and $15 \mathrm{~s}$, as well as four band-pass filters with overlapping frequencies: $1-7 \mathrm{~Hz}, 5-10 \mathrm{~Hz}, 8-15 \mathrm{~Hz}$, and $12-20 \mathrm{~Hz}$. An example of automatic picking is illustrated in Figure 4 for stations MBFR, MBLY, and MBBY. The estimated kurtosis function is shown at each frequency band for station MBFR in Figure 4a, and the integrated 

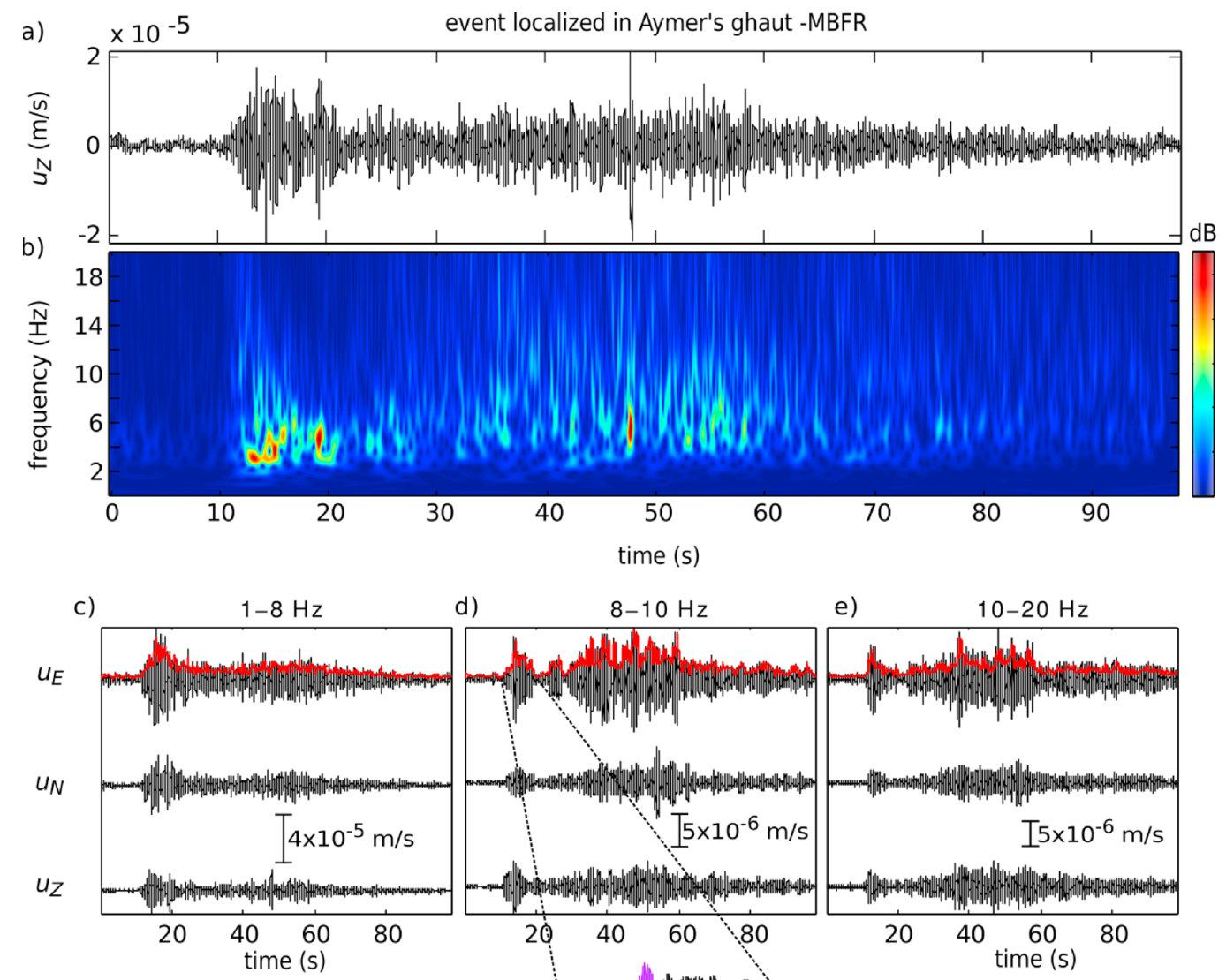

d) $8-10 \mathrm{~Hz}$

e) $\quad 10-20 \mathrm{~Hz}$
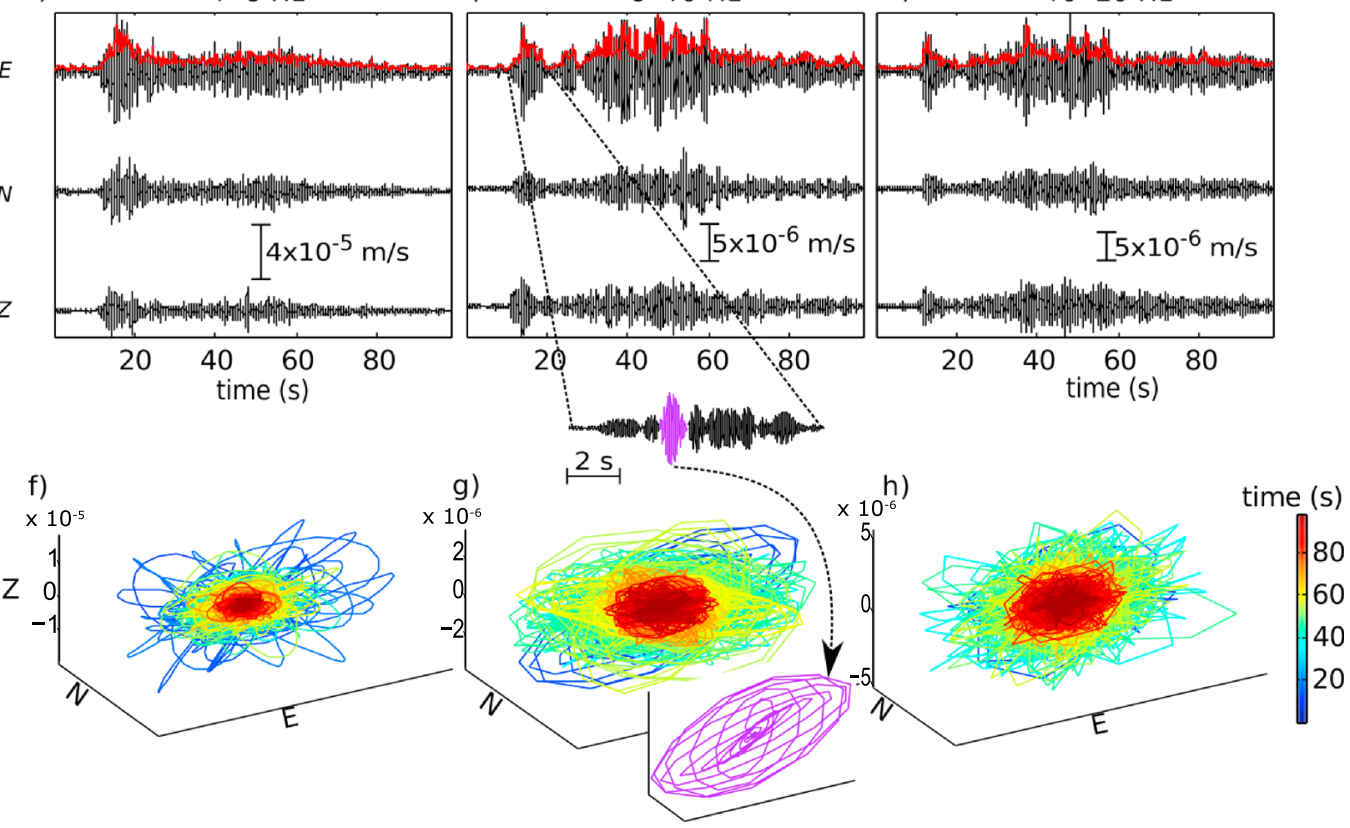

Figure 3. Characteristics of the seismic signal of a granular flow. (a) Seismic signal of the granular flow represented by a star in Figure 1 as recorded at station MBFR $1.7 \mathrm{~km}$ away (vertical component). This event is also used as an example in Figure $9 \mathrm{e}$ and in Figures 4 and 5 and in Figure A2 in Appendix A. (b) The associated $S$ transform. (c-e) Seismic records of the same event for frequency bands $1-8 \mathrm{~Hz}, 8-10 \mathrm{~Hz}$, and $10-20 \mathrm{~Hz}$, respectively. The Hilbert envelope of the eastern component is plotted in red. ( $f-h)$ The polarization plots for the frequency bands corresponding to Figures $3 c-3 e$. The identification of wave packets is difficult in this type of signal, although some transient phenomena can be spotted at high frequencies. An example of an impulsive part of the signal is plotted in purple in the zoom of Figure $3 \mathrm{~d}$. The corresponding wave arrivals can be identified on the zoom of the polarization plot of Figure $3 \mathrm{~g}$.

kurtosis function for all frequency bands is shown for stations MBFR, MBLY, and MBBY in Figures $4 b-4 d$. In this example, the signal-to-noise ratio (SNR) is reasonably high for all stations (the SNR being considered here as the ratio between the mean amplitude of the first $10 \mathrm{~s}$ of the signal and the mean amplitude of the $10 \mathrm{~s}$ preceding the event). When the SNR value drops below 2.5 , the picking procedure becomes unreliable. The end of each rockfall signal was considered to be the time at which the smoothed Hilbert envelope of the signal recovers its preevent value. The Hilbert envelope is smoothed using a $5 \mathrm{~s}$ averaging filter.

\subsection{Locating Source Areas Using the Fast Marching Method}

The observed time delays were used to locate the source areas by applying the fast marching method (FMM) [Sethian, 1996; Hibert et al., 2014b]. The FMM is a numerical technique for computing the position of 

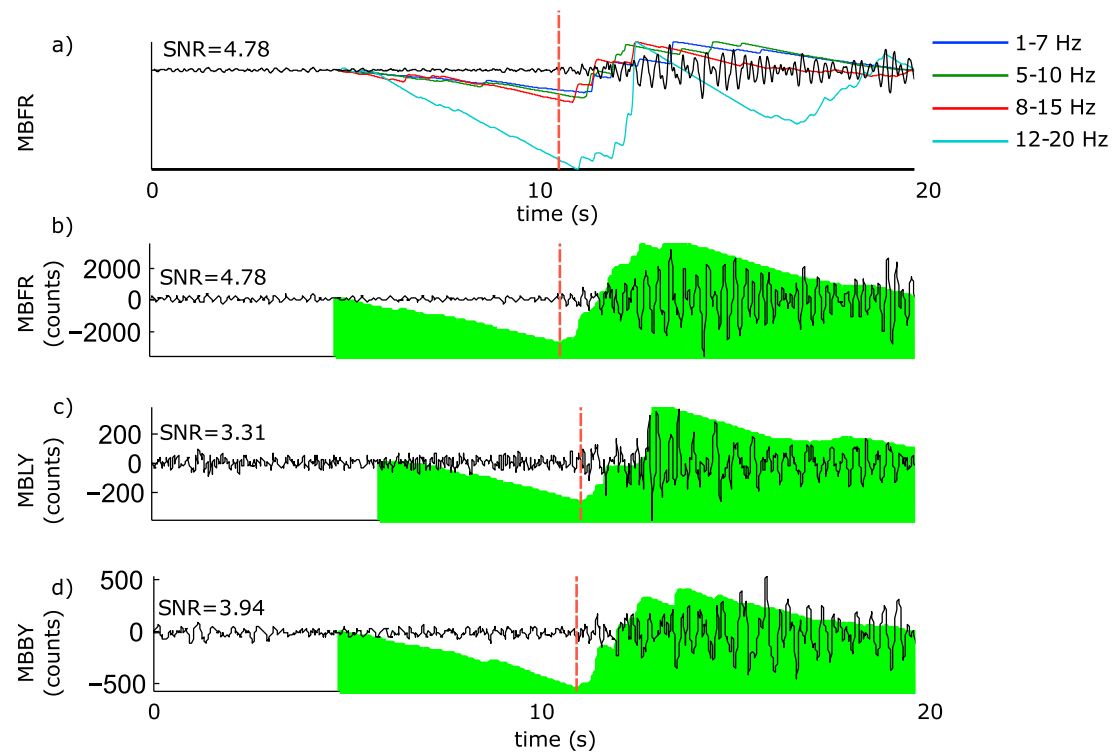

Figure 4. Automatic picking of an event located in Aymer's ghaut.(a) Example of automatic picking (red vertical line) of an event located in Aymer's ghaut (see Figures 1 and 3) on the seismic record of station MBFR (vertical component). The picking procedure is based on the average of the estimated kurtosis function at four different frequency bands (see legend). (b-d) Examples of automatic picking (red vertical line) on the vertical components of stations MBFR, MBLY, and MBBY for the same event as in Figure 4a. The averaged kurtosis function for all frequency bands is displayed as green areas.

propagating fronts that uses an extremely fast scheme for solving the Eikonal equation. Without going into detail, the FMM allows us to estimate grids of travel times from each MVO seismic station at a given wave velocity (see the example in Figure 5a). To solve the problem, we consider a medium with homogeneous velocity, where rockfall signals are mainly related to surface waves. As surface waves propagate along the topography, the computed travel times depend strongly on the topography. Computations use a digital elevation model based on aerial lidar data acquired by the MVO in 2008. Grid spacing is $10 \mathrm{~m}$.

It is now possible to compute delay maps for each station pair, corresponding to the difference in travel times between the two stations of each pair (see the example in Figure $5 \mathrm{~b}$ ). The observed time delay for a pair of stations can be reported on the corresponding delay map, thus appearing as a hyperbola (see the example in Figure 5c). The width of the hyperbolas takes into account the potential errors in the estimation of time delays. For each event, the positions of the hyperbolas corresponding to all the observed time delays are plotted, and the result is stacked on one single map (see the example in Figure $5 \mathrm{~d}$ ). When an event can be located, three or more hyperbolas intersect, thus delineating a source area. The possibility of delineating a source area is considered for a realistic range of surface wave velocities. Locating is thought to be optimal for the wave velocity at which the largest number of hyperbolas intersect with a minimum difference between observed and computed time delays (to be more specific, it is the root-mean-square of these differences that is minimized; see Figure 5 e).

This method using hyperbolas was preferred over a random search of epicenter locations within the grid by minimizing the RMS of the differences between observed and computed time delays. The advantages of this method are as follows: (1) the maps are computed relatively quickly, as only simple operations are performed on already existing grids that can be reused for different events and (2) this method excludes aberrant time arrivals from the locating process, as the corresponding hyperbolas will not focus. The uncertainties on the epicenter locations are directly proportional to the estimated RMS.

Locating was possible only when the signal-to-noise ratio (SNR) was sufficiently high for multiple stations (SNR > 2.5), i.e., only for 46 events out of 200. The epicenters of the events that could be located are reported on the map in Figure 1 with an error represented by the size of the red circles.

In most cases, this error is about the same size as the dot representing the epicenter, i.e., around $80 \mathrm{~m}$. 

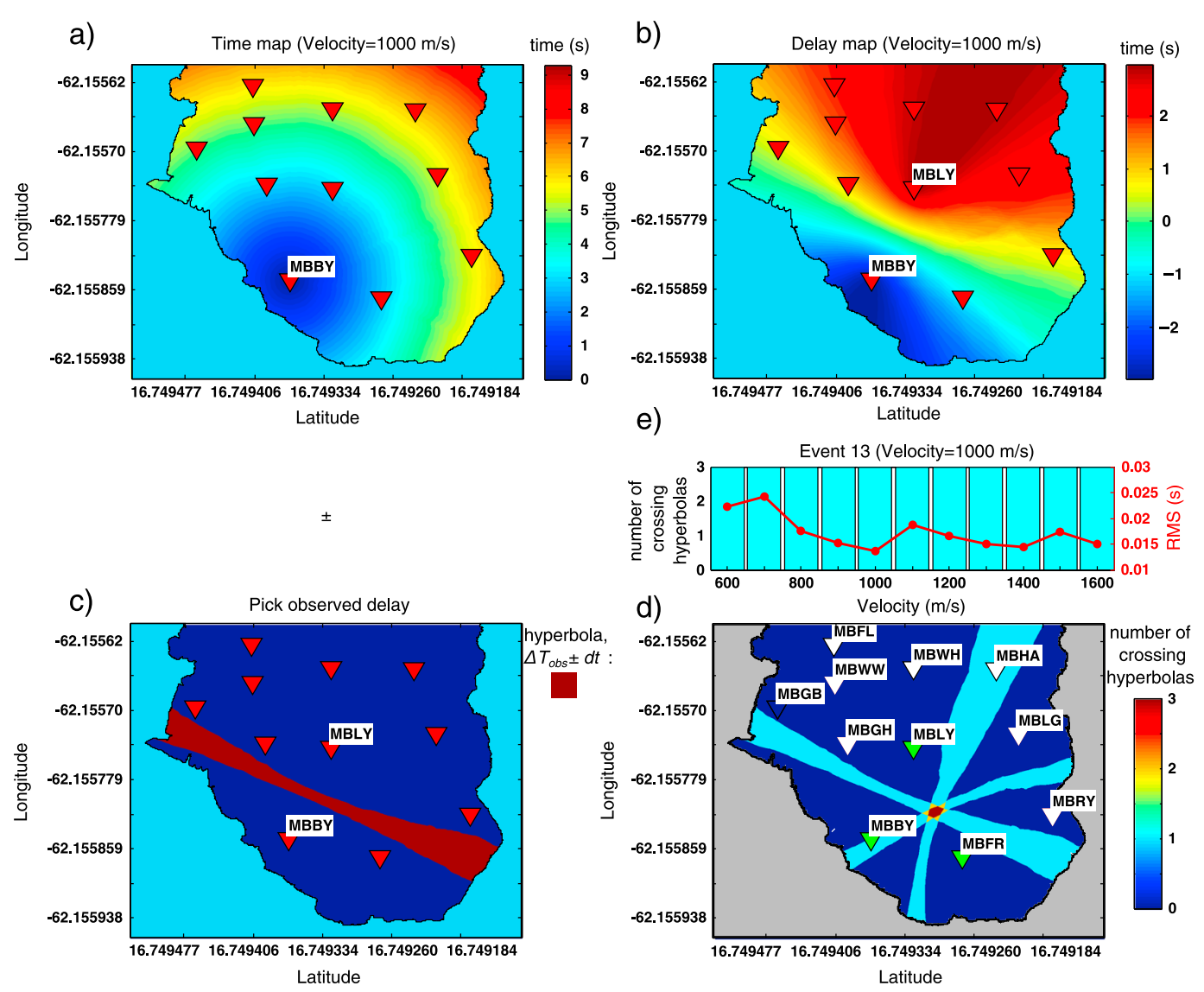

Figure 5. Locating of an event using the fast marching method. (a) Travel time map from station MBBY for a homogenous surface wave velocity of $1000 \mathrm{~m} / \mathrm{s}$. Travel times were estimated by applying the FMM on a digital elevation model (DEM) grid with $10 \mathrm{~m}$ spacing. (b) Delay map between stations MBBY and MBLY for a homogenous surface wave velocity of $1000 \mathrm{~m} / \mathrm{s}$, deduced from the travel time maps of both stations. (c) The observed delay $\Delta T_{\text {obs }}$ between arrival times at stations MBBY and MBLY for an event in Aymer's ghaut (presented in Figures 1 and 3 ) is reported on the delay map. Values matching $\Delta T_{\text {obs }} \pm \mathrm{d} t$ are set to 1 , where $\mathrm{d} t=0.3 \mathrm{~s}$ is the worst picking error possible for $\mathrm{SNR}=2.5$. This process makes it possible to plot a hyperbola (in red) with a width that takes into account the potential errors on the estimation of time delays. (d) The observed delays between stations MBLY, MBBY, and MBFR are reported on a single map, thus leading to three distinct hyperbolas. The hyperbolas intersect close to the Soufrière Hills Volcano summit, constraining the probable location of the source area (in red). (e) Number of crossing hyperbolas and RMS value as a function of the surface wave velocity used to compute the FMM delay maps.

Most epicenters are located on the western flank of the Soufrière Hills Volcano, with a large majority of events occurring within Gages and Aymer's ghauts (blue and green epicenters in Figure 1). The event distribution is consistent with the MVO report of activity for the same period, indicating a switch in the direction of the dome growth from south-west to west in early November 2009 (2009 MVO activity report, http://www.mvo.ms/pub/Open_File_Reports/MVO_OFR_13_04-MVO_Activity_Reports_2009.pdf).

\section{Power Law Between Seismic Energy and Signal Duration}

\subsection{Seismic Power Law}

In order to potentially identify power law (1), we estimate the seismic energy and the duration of the events. Because the objective is to extract quantitative information from the power law in terms of landslide rheology, it is important to reduce the uncertainties in the energy calculation as much as possible, as well as to quantify and understand the scattering of the data.

Calculating seismic energy and signal duration is an important issue in seismology [Trifunac and Brady, 1975; Pousse et al., 2006; Kanamori, 1977; Singh and Ordaz, 1994; Izutani and Kanamori, 2001]. We estimated the duration of each event using the automatic method explained in the section 2.4. As the picking may differ from one station to another, the duration $t_{s}$ is chosen as the average duration over all the stations. Picking 
differences are typically within the range of a few seconds $(<5 \mathrm{~s})$, which is small compared to the total rockfall durations (30 to $350 \mathrm{~s}$ ).

To estimate the seismic energy, we assume a point-source [Kanamori and Given, 1982; Eissler and Kanamori, 1987; Dahlen, 1993; Favreau et al., 2010; Moretti et al., 2012; Zhao et al., 2012] and we consider the medium as isotropic and homogeneous. We also assume that surface waves dominate the seismic signal and use the same relation as [Hibert et al., 2011, 2014b]:

$$
E_{s}=2 \pi r \rho h c \int_{t_{1}}^{t_{2}} u_{\text {env }}(t)^{2} e^{\alpha r} \mathrm{~d} t
$$

with

$$
u_{\text {env }}(t)=\sqrt{u(t)^{2}+H t(u(t))^{2}}
$$

where $t_{1}$ and $t_{2}\left(t_{s}=t_{2}-t_{1}\right)$ are the picked onset and final times of the seismic signal, respectively, $r$ is the distance between the event and the recording station, $h$ is the thickness of the layer through which surface waves propagate, $\rho$ is the density of the ground, $c$ is the group velocity of the seismic waves (and not the phase velocity as in Hibert et al. [2011]), $\alpha$ is a damping factor that accounts for anelastic attenuation of the waves [Aki and Richards, 1980], and $u_{\mathrm{env}}(t)$ is the amplitude envelope of the ground velocity obtained using the Hilbert transform $(H t)$.

The energy is computed using the three components of the signal $\left(u=\sqrt{u_{E}^{2}+u_{N}^{2}+u_{Z}^{2}}\right)$. It is designated $E_{s}$ freq' as the parameters $h$ and $\alpha$ are considered to be frequency dependent. For each event, the seismic energy is averaged for all the stations to obtain a mean value of $E_{s}$ freq. The density is approximated at $2000 \mathrm{~kg} / \mathrm{m}^{3}$. The source-station distance $r$ is deduced from the location of the events, and we assume an initiation at the Soufrière Hills Volcano summit for the events that could not be located. We assume that the signal is mostly made of Rayleigh waves, even though this is very difficult to observe on the recorded signal (see Figure 3). Because the velocity model is insufficiently constrained, we assume that the wave velocity is constant and slightly smaller than the shear wave velocity $V_{s}: c \approx 0.9 V_{s}=1300 \mathrm{~m} / \mathrm{s}$. In that case, the thickness of the layer through which surface waves propagate can be approximated by $h(f) \simeq 2.5 c / f$ [Lay and Wallace, 1995]. By using the seismic records of the located rockfalls at different stations, we empirically estimate $\alpha$ as a function of the frequency (see Appendix A):

$$
\alpha=A f^{\gamma}
$$

with $A=2.4 \times 10^{-4} \pm 2.4 \times 10^{-5} \mathrm{~m}^{-1}$ and $\gamma=0.4 \pm 0.04$. For frequency bands between 0.5 and $19.5 \mathrm{~Hz}, \alpha$ ranges from $2.2 \times 10^{-4}$ to $8.7 \times 10^{-4} \mathrm{~m}^{-1}$.

The resulting seismic energy is plotted as a function of the seismic signal duration for each of the 200 rockfalls in Figure 6a. It ranges from $10^{5}$ to $10^{8} \mathrm{~J}$, covering 4 orders of magnitude. The duration varies from 29 to $347 \mathrm{~s}$. Despite strong scattering of the data, we roughly identify the scaling law $E_{s}$ freq $\propto t_{s}^{\beta}$ (grey line in Figure 6a). The corresponding regression coefficient is $\beta=2.5$ with $R^{2}=0.54$, indicating a weak relationship between $E_{s}$ freq and $t_{s}$. However, the $p$ value of the model is very small compared to 0.01 ( $p$ value $=10^{-29}$ ), supporting the hypothesis that a relationship between $E_{s}$ freq and $t_{s}$ is likely to exist in the form of the power law (1). Indeed, $p$ values are here designed for testing the hypothesis of no correlation between $\log \left(E_{s}\right.$ freq $)$ and $\log \left(t_{s}\right)$ against the alternative that there is a nonzero correlation. As the $p$ value is small, we can say that this correlation is significantly different from zero [Gibbons, 1985]. The scattering of the seismic energy values around the regression line covers 2 orders of magnitude. An empirical variance of $\beta=2.5 \pm 0.35$ and $R^{2}=0.54 \pm 0.05$ was estimated by performing one thousand bootstrap resamplings [Bates and Watts, 1988].

\subsection{Differences in Seismic Energy Calculations and Power Law Dispersions}

We present here the estimation of the seismic energy $E_{s}$ when the parameters $h, c$, and $\alpha$ are considered constant (as in Hibert et al. [2011, 2014b]), as well as the estimation of the seismic energy $E_{s z}$ when only the vertical component $u_{z}(t)$ is used. The results are compared with the estimation of the seismic energy $E_{s \text { freq }}$ presented in section 3.1 .

To estimate $E_{s}$, we take $c=1300 \mathrm{~m} / \mathrm{s}$, consistent with Jollyet al. [2002], $\alpha=f \pi / Q c$, with $f=5 \mathrm{~Hz}$ corresponding to the central frequency of the events, and $Q=20$, as roughly estimated by Jolly et al. [2002] for the Soufrière Hills Volcano and corresponding to a typical value for the attenuation of surface waves in andesitic volcanoes. 

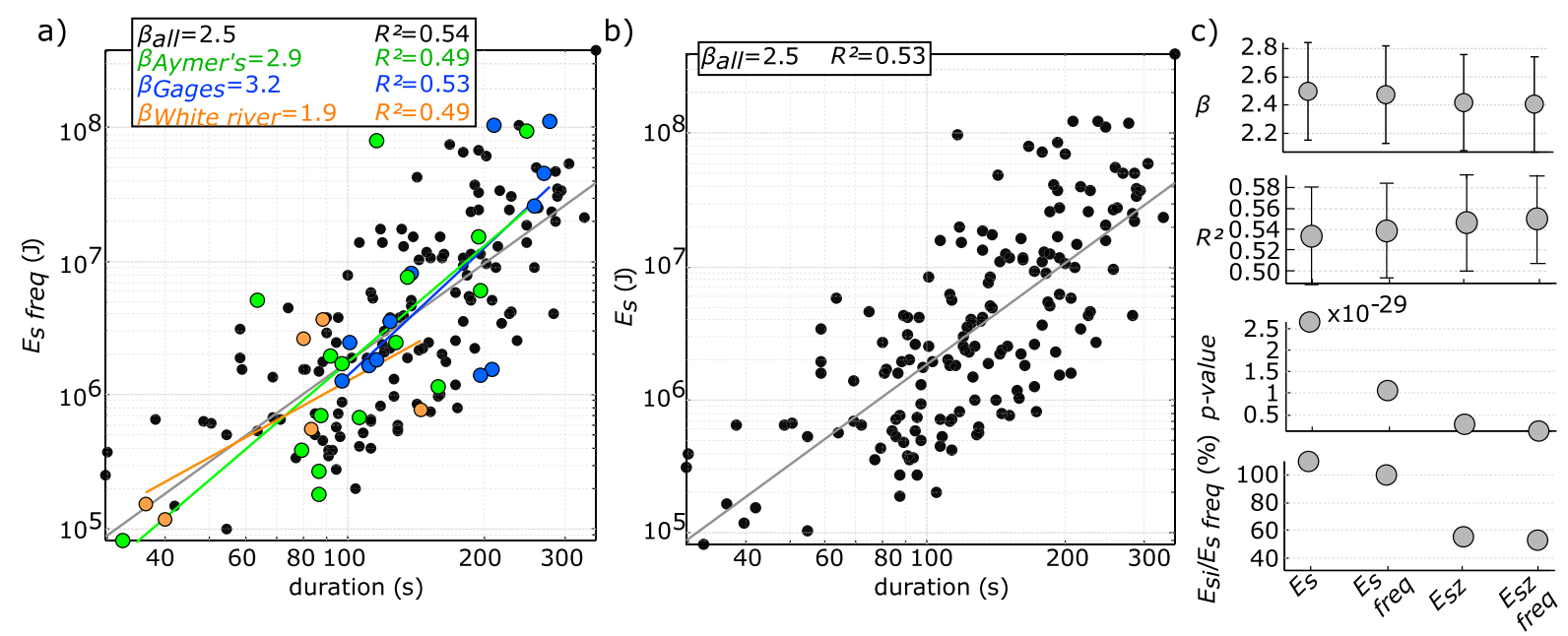

Figure 6. The power law (1) for $E_{s}$ and $E_{s \text { freq. }}$ (a) Seismic energy $E_{s}$ freq estimated using frequency-dependent parameters $(h$ and $\alpha)$ as a function of the signal duration $t_{s}$ for the 200 recorded granular flows averaged over all the stations. Best fit regression lines (solid lines) and power law coefficients $\beta$ and associated $R^{2}$ values are indicated in the legend. (b) Seismic energy $E_{s}$ as a function of the signal duration $t_{s}$ for the 200 recorded granular flows averaged over all the stations.

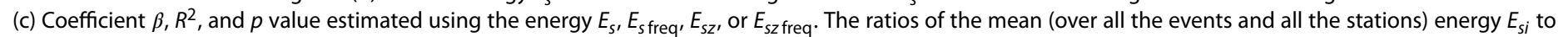
the mean energy $E_{s \text { freq }}$ are plotted as percentages $\left(E_{s i}=\left[E_{s}, E_{s \text { freq }}, E_{s z}, E_{s z \text { freq }}\right]\right)$.

This gives $\alpha=6.0 \times 10^{-4} \mathrm{~m}^{-1}$. The depth is assumed to be $h=260 \mathrm{~m}$, corresponding to one wavelength of Rayleigh waves at $f=5 \mathrm{~Hz}$ and $c=1300 \mathrm{~m} / \mathrm{s}$.

The resulting seismic energy $E_{s}$ is plotted as a function of the seismic signal duration $t_{s}$ in Figure $6 \mathrm{~b}$. The dispersion is very similar to that found for $E_{\text {sfreq }}$ (Figure 6a), although slightly higher as $R^{2}=0.53$ compared to $R^{2}=0.54$ for $E_{\text {sfreq }}$. For both computations of the seismic energy, the empirical variance of $R^{2}$ (determined using bootstrap resampling) is 0.05 . Thus, the frequency dependence of the parameters does not explain the main part of the dispersion in the data. Moreover, taking into account frequency-dependent parameters do not change the coefficient of the power law as shown in Figure $6 c$. Indeed, here $\beta=2.5 \pm 0.33$ instead of $2.5 \pm 0.35$. However, the energy is slightly overestimated (110\%) when the parameters of the energy calculation are considered to be constant (Figure $6 c$, fourth panel).

To calculate $E_{s z}$, we assume that all the components have about the same amplitude, so that $u=\sqrt{3} u_{z}$. The objective is also to quantify the error in the energy calculation made when using only $u_{z}$ (as done, for example, in Hibert et al. [2011]). Indeed, it is common to have only seismic stations with one component (vertical) and for three component stations, the horizontal components may be very noisy [Bonnefoy-Claudet et al., 2006]. We observe that the energy $E_{s z}$ calculated with the vertical component is about half of the total energy (Figure $6 c$ ). The reason is that the horizontal components of the signal generally have a higher amplitude than the vertical component (see Figure 3). The value of $\beta$ is, however, not very different (Figure $6 c$, first panel). On the other hand, the dispersion is smaller when using only the $Z$ component, possibly because the signal is generally less noisy on the vertical component. As for the total energy, the energy $E_{s z}$ and the associated power law changes only very slightly when frequency-dependent parameters are taken into account (Figure 6c).

\subsection{Origin of the Scattering in the Power Law}

To assess the relevance of the power law, the origin of the scattering of the data must be understood. This scattering could be due to errors in picking the signal duration and to the approximations made in the energy computation (presence of body waves, 3-D variations of the seismic velocities, and density). Another crucial point is the topography over which the granular mass is flowing, which has been shown to change the coefficient of the power law [Hibert et al., 2011]. We focus on this aspect, as we may expect different power laws for rockfalls flowing within different valleys. To check this, we differentiate between the rockfalls located in different valleys, keeping only the valleys where a minimum of six events were located. Even though we have a very small number of points (16 events in Aymer's ghaut, 12 in Gages ghaut, and 6 in the White River valley), we observed different coefficients for each valley, i.e., $\beta_{\text {Aymer's }}=2.9 \pm 1.6, \beta_{\text {Gages }}=3.2 \pm 1.7$, and $\beta_{\text {White }}=1.9 \pm 2.8$. Hibert et al. [2011] showed that the value of $\beta$ decreases with increasing rugosity of the topography. This is compatible with our observations because the profiles of Aymer's ghaut and Gages ghaut are very similar 


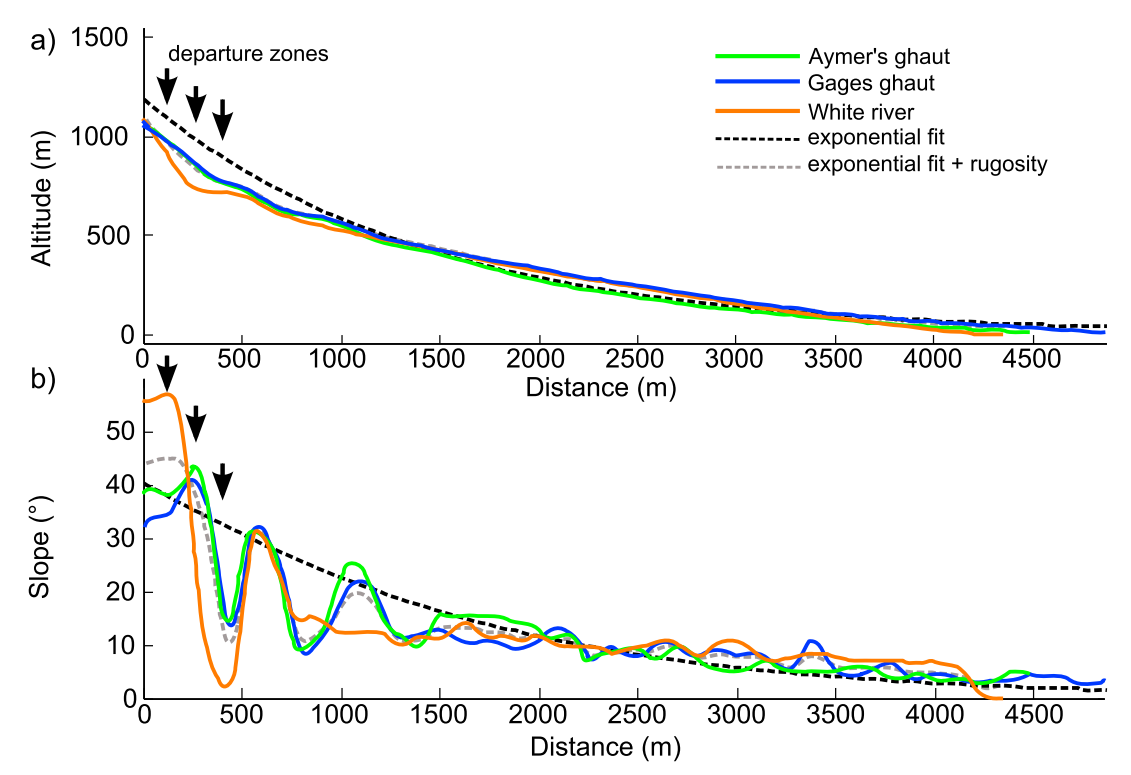

Figure 7. Two-dimensional profiles used in the simulations of granular flows. (a) Two-dimensional profiles of the main valleys of the Soufrière Hills Volcano (extracted from a $1 \mathrm{~m}$ gridded digital elevation model (DEM) and slightly smoothed using a 20 points averaging filter), together with an exponential fit of the mean profile of these three valleys (black dashed line), as well as this exponential fit with added rugosity (grey dashed line). The rugosity corresponds to the mean topographical features of the profiles of Aymer's ghaut, Gages ghaut, and White River filtered above $100 \mathrm{~m}$. Departure positions of simulated granular flows are indicated by arrows. (b) Variation of the slope angle with the horizontal distance along the profiles.

while the fluctuation of the slope in the White River valley is greater (Figure 7). Even with these different values of $\beta$, the scattering of the points for one valley is not smaller than for all the data together, as indicated by the $R^{2}$ values (from 0.49 to 0.53 , with an empirical variance determined using bootstrap resampling ranging from 0.2 to 0.26 ).

These results show that we observe the same power laws as those observed in the very different context of rockfalls at Piton de la Fournaise with coefficients $\beta$ of the power law strongly related to the local topography over which the masses flow [Hibert et al., 2011]. For Montserrat and Reunion Island, these coefficients range between $1.8<\beta<3.2$.

\section{Friction Weakening in Granular Flows and Topography Explain Seismic Observations}

As in Hibert et al. [2011], we perform a series of numerical simulations of granular flows over the topography of the different valleys to test for evidence of a power law similar to (2) between the loss of potential energy $\Delta E_{p}$ of the mass and the duration of the flow $t_{f}$. The general idea is to constrain the friction coefficient in the granular flow model to reproduce the power law (2) with the same coefficient $\beta$ as that observed using seismic data (power law (1)). Numerical simulations are also expected to give insight into the topography effects on flow dynamics and into the origin of the scattering observed in the seismic power law.

\subsection{Numerical Simulations}

We used the SHALTOP numerical model, which describes dry granular flows over a complex 3-D topography [Bouchut et al., 2003; Bouchut and Westdickenberg, 2004; Mangeney-Castelnau et al., 2005; Mangeney et al., 2007]. This model is based on a depth-averaged thin-layer approximation (the flow is assumed to be thin compared to its longitudinal extent). It describes the change of flow thickness with time $h(x, y, t)$ in the direction normal to the topography and the depth-averaged velocity of the flow $u(x, y, t)$ along the topography $z=b(x, y)$ where $(x, y, z)$ are the coordinates in a Cartesian reference frame. This model deals with the full tensor of terrain curvature. SHALTOP has successfully reproduced experimental granular flows [Mangeney-Castelnau et al., 2005; Mangeney et al., 2007] and natural landslides [Lucas and Mangeney, 2007; Kuo et al., 2009; Mangold et al., 2010; Favreau et al., 2010; Lucas et al., 2011]. 
SHALTOP uses a Coulomb-type friction law with a friction coefficient $\mu=\tan \delta$, where $\delta$ is the friction angle. This friction coefficient can be considered as a measure of the effective dissipation during the flow [Mangeney et al., 2010; Lucas et al., 2014]. We carried out simulations using either

1. a constant friction coefficient for all rockfalls or

2. a friction coefficient that varies with the landslide volume $V$ approximately as [Lucas et al., 2014]:

$$
\mu=\frac{1}{V^{0.0774}}
$$

This variation of the friction coefficient with the landslide volume (equation (6)) is an empirical law determined by Lucas et al. [2014] by fitting runout distances for small to very big landslides occurring within different contexts, including extraterrestrial landslides.

We simulated 2-D flows created by the release of a parabolic mass from rest over the along-slope profiles of Aymer's ghaut, Gages ghaut, and White River extracted from a $1 \mathrm{~m}$ gridded digital elevation model, slightly smoothed using a 20 point averaging filter (Figure 7). These valleys correspond to the most common flow paths during the three days of records. Simulations were also done over an exponential profile fitted on the mean profiles of these three valleys with and without added rugosity. The added rugosity corresponds to the mean topographical features of the three profiles filtered above $100 \mathrm{~m}$. For each profile, we varied the position of the released mass (top, middle, and bottom of the released area) and its volume (from 500 to $10^{6}$ $\mathrm{m}^{3}$ ), according to geological observations. The potential released areas are represented in grey in Figure 1. For each simulation, we calculated the loss of potential energy $\Delta E_{p}$ of the mass between the initial instant $t=0 \mathrm{~s}$ and the final state $t_{f}$ when the deposit has formed. The flow duration $t_{f}$ is calculated by assuming that the mass is at rest when the maximum velocity is lower than $0.1 \mathrm{~m} / \mathrm{s}$ for a flow thickness higher than $10 \mathrm{~cm}$. Note that simulations using SHALTOP do not take into account erosion processes that may increase the flow duration [Mangeney et al., 2010]. Furthermore, only single collapses are simulated here even though successive collapses may be mixed up in one event [Moretti et al., 2015].

\subsection{Conversion of Potential to Seismic Energy}

Figure 8a shows $\Delta E_{p}\left(t_{f}\right)$ for three series of simulations on the Aymer's ghaut profile using three different friction angles $\delta=20^{\circ}, \delta=30^{\circ}$, and $\delta=35^{\circ}$ (orange, blue, and red dots, respectively). These values are in the range of the friction angles measured during laboratory experiments using samples from the Soufrière Hills Volcano [Voight et al., 2002]. Each point cloud is fitted using a robust fit algorithm (dashed lines of slope $\beta$ ). This algoritm uses iteratively reweighted least squares with a bisquare weighting function (2015 MATLAB documentation web page on robust fit, http://fr.mathworks.com/help/stats/robustfit.html). Interestingly, none of these three series of simulations reproduces the seismic power law $E_{s}\left(t_{s}\right)$ (green dots and solid line in Figure $8 \mathrm{a}$ ). When $\delta \geq 30^{\circ}$, the simulated large volumes (i.e., $10^{6} \mathrm{~m}^{3}$ ) tend to stop at distances much shorter than those observed in the field. As a result, the associated flow duration $t_{f} \leq 80 \mathrm{~s}$ is too short given that large volumes usually have signal durations $t_{s}>200 \mathrm{~s}$. For such friction angles, the simulated flow durations of small volumes $\left(500-3000 \mathrm{~m}^{3}\right)$ are, however, reasonably consistent with seismic observations $\left(20 \leq t_{f} \leq 30 \mathrm{~s}\right)$. On the other hand, when $\delta=20^{\circ}$, simulations of large volumes (i.e., $10^{6} \mathrm{~m}^{3}$ ) lead to flow durations more consistent with seismic observations while small volumes run too far and have flow durations longer than those observed $\left(t_{f} \geq 60 \mathrm{~s}\right.$ ). Thus, whatever the chosen friction coefficient, the simulations using a constant friction coefficient for all rockfalls cover a range of durations much narrower than the durations of the generated seismic signal. The approximations of the SHALTOP model might be the cause of the difference between simulations and seismic observations, as nonhydrostatic forces are not completely included in the shallow water formulation. In principle, nonhydrostatic forces will slow down the flow, as in hydrostatic, the free surface gradient (which is a driving force) is always overestimated. However, we believe it unlikely, as in the literature, all models, whether continuous or discrete, need to use very low friction coefficient to reproduce the runout distances of large landslides [Smart et al., 2010; Lucas et al., 2014].

Instead of a constant friction coefficient for all rockfalls, we will now use the variable friction coefficient given by relation (6). The color of each symbol in Figure $8 \mathrm{~b}$ corresponds to the value of the friction angle $\delta$ and its shape (circle, square, or triangle) to the departure zone (bottom, middle, and top, respectively). The use of a variable friction coefficient gives a range of simulated durations ( $21 \leq t_{f} \leq 219 \mathrm{~s}$ ) similar to the seismic durations observed in Aymer's ghaut $\left(29 \leq t_{s} \leq 347 \mathrm{~s}\right.$ ). The best fit of $\Delta E_{p} \propto t_{f}^{\beta}$ gives $\beta_{p}=2.7 \pm 1.8$, very close to $\beta_{s}=2.9 \pm 1.6$ obtained from seismic data for the events located in Aymer's ghaut (green dots and 

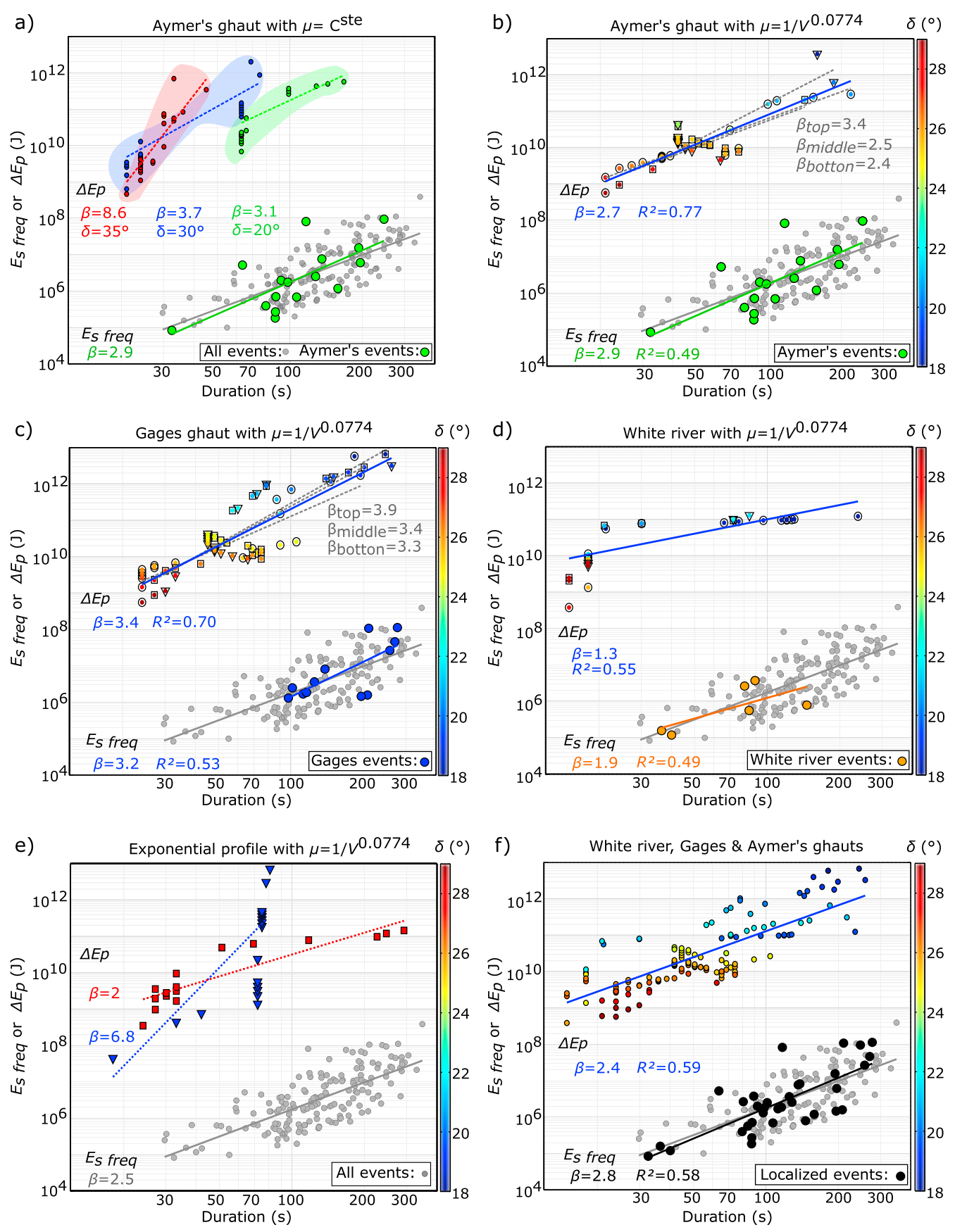

Figure 8. The loss of potential energy $\Delta E_{p}$ for simulations at the Soufrière Hills Volcano. (a) $\Delta E_{p}$ as a function of the flow duration $t_{f}$ for simulations in Aymer's ghaut compared to the seismic energy $E_{s \text { freq }}$ as a function of signal durations $t_{s}$ for the 200 recorded granular flows. Three series of simulations were performed with friction angles $\delta=20^{\circ}, 30^{\circ}$, and $35^{\circ}$, respectively. (b) Same as Figure 8 a but for simulations using a friction angle $\delta$ dependent on the volume (equation (6)). Best fit regression lines and power law coefficients $\beta$ are indicated on the plots, together with the regression statistic $R^{2}$. (c and d) Same plot as in Figure 8b but for simulations along the profiles of Gages ghaut and White River. (e) Ditto for simulations along the exponential fit profile (triangles) and the same profile with added rugosity (squares). (f) Ditto for a mix of simulations along Aymer's ghaut, Gages ghaut, and White River.

line in Figure $8 \mathrm{~b}$ ). When calculating different values of $\beta_{p}$ for simulations corresponding to different departure zones in Aymer's ghaut, we find $\beta_{p}=3.43, \beta_{p}=2.45$, and $\beta_{p}=2.41$ when the mass is released from the top, middle, and bottom, respectively (Figure $8 b$ ). These results show that different departure zones may induce scattering in the observed power law and variability in the value of $\beta$. 


\begin{tabular}{|c|c|c|c|}
\hline$R_{s / p \text { Aymer's }}$ & $R_{s / p \text { Gages }}$ & $R_{s / p \text { W.River }}$ & $R_{s / p \text { All }}$ \\
\hline $2.78 \times 10^{-5}$ & $1.11 \times 10^{-5}$ & $1.25 \times 10^{-5}$ & $1.52 \times 10^{-5}$ \\
\hline
\end{tabular}

A similar series of simulations was conducted on Gages ghaut and White River profiles as shown in Figures $8 \mathrm{c}$ and $8 \mathrm{~d}$, respectively. Despite the small number of located events (12 events in Gages ghaut and 6 events in the White River valley), the slope $\beta_{p}$ obtained from the simulations $\Delta E_{p}\left(t_{f}\right)$ when using a variable friction coefficient is very close to the value obtained from seismic data by fitting $E_{s}\left(t_{s}\right)$. For Gages ghaut, $\beta_{s}=3.2 \pm 1.7$ and $\beta_{p}=3.4 \pm 1.5$ and for White River, $\beta_{s}=1.9 \pm 2.8$ and $\beta_{p}=1.3 \pm 2.5$.

The value of $\beta$ is thus closely related to the topography over which the granular mass flows. Indeed, for simulations over a smooth exponential profile fitted on the mean profiles of the valleys (see Figure 7), we obtain $\beta_{p}=6.8$, much larger than $\beta_{s}=2.5$ (Figure 8e). Moreover, the range of durations of the flow in the simulations ( $18 \leq t_{f} \leq 81 \mathrm{~s}$ ) is not consistent with seismic observations ( $\left.29 \leq t_{s} \leq 347 \mathrm{~s}\right)$. On the other hand, when a mean roughness is added to this exponential profile (Figure 7), the simulations are more consistent with the seismic observations with $\beta_{p}=2$ and $24<t_{f}<289 \mathrm{~s}$.

Plotting the seismic data and numerical simulations for all the valleys together, Figure $8 \mathrm{f}$ shows again that $\beta_{p}=2.4 \pm 0.8$ and $\beta_{s}=2.8 \pm 1.3$ are close. Interestingly, the scattering of the seismic and simulated power laws is also quite similar, with $R^{2}=0.58 \pm 0.1$ for seismic data and $R^{2}=0.59 \pm 0.06$ for simulations. Furthermore, the fluctuation of the potential energy around its mean value is of 2 orders of magnitude, like the scattering of the seismic energy. The scattering of the seismic data $E_{s}\left(t_{s}\right)$ is likely due to the different valleys and departure zones and to the scattering of the power law $\Delta E_{p}\left(t_{f}\right)$ for a given valley and departure zone.

Numerical simulations of granular flow with a friction coefficient dependent on the landslide volume (see equation (6)) allowed to reproduce better the seismic observations. In the literature, several mechanisms have been proposed to explain the friction reduction under certain conditions for landslides, such as lubrication by water or air, thermal pressurization, fragmentation, acoustic fluidization, flash heating, or erosion [Legros, 2002; Singer et al., 2012; Davies, 1982; Tsutsumi and Shimamoto, 1997; Lucas and Mangeney, 2007; Lucas et al., 2014].

Our models do not take into account the full complexity of natural flows. In particular, we do no model erosion that has been shown to increase runout distances for granular flows on slopes higher than about half of their friction angle, which is the case at Montserrat [Mangeney et al., 2010; Farin et al., 2014]. Since erosion efficiency increases with the volume involved, part of the apparent friction weakening may be explained by erosion effect. With the current knowledge, it is not possible to quantify this effect.

Lucas et al. [2014] showed that another physical process that could well explain this volume-dependent friction law for granular flows is an actual frictional weakening with increasing slip velocity. A micromechanical process that can lead to dramatic velocity weakening is flash heating [Lube et al., 2004; Moretti et al., 2012]. The real contact between two rough solid surfaces generally occurs over a small fraction of their nominal contact area, on highly stressed microcontacts (asperities). Slip produces frictional heating at the microcontact scale. If slip is fast enough to prevent heat dissipation by conduction, the microcontact experiences a significant transient temperature rise that activates thermal effects such as melting, dehydration, or other phase transformations. This reduces the local shear strength of the microcontact and leads to a macroscopic decrease of the friction coefficient as a function of sliding velocity.

4.3. The Ratio $R_{s / p}=E_{s} / \Delta E_{p}$, Comparison With Other Studies

The strong similarity of the relations $E_{s}\left(t_{s}\right)$ and $\Delta E_{p}\left(t_{f}\right)$ suggests a constant transfer of potential to seismic energy for these granular flows, as observed at Piton de la Fournaise. The ratio $R_{s / p}=E_{s} / \Delta E_{p} \simeq 10^{-5}$ is almost constant for all the valleys (Table 1 ), showing that only a small portion of the potential energy released is converted into seismic energy. Our ratio $R_{s / p}=E_{s} / \Delta E_{p}$ at Montserrat is of the same order of magnitude as the ratios found by Deparis et al. [2008] (essentially ranging from $10^{-5}$ to $10^{-4}$ ) for 10 rockfalls recorded by a regional seismological network in the Alps with volumes $2 \times 10^{3}<V<1.75 \times 10^{6} \mathrm{~m}^{3}$ and source-station distances $10<d<100 \mathrm{~km}$, by Hibert et al. [2011] $\left(10^{-5}<R_{s / p}<10^{-3}\right)$ for granular flows at the Piton de la Fournaise volcano with $1<V<5 \times 10^{3} \mathrm{~m}^{3}$ and $0.3<d<2.1 \mathrm{~km}$ and by Berrocal et al. [1978] $\left(R_{s / p} \simeq 10^{-6}\right)$ for the 1974 Mantaro slide in Peru with $d>80 \mathrm{~km}$. 
When comparing in detail with Piton de la Fournaise, for a given seismic (or flow) duration, the seismic energy is 1 order of magnitude higher in Montserrat and the loss of potential energy is more than 2 orders of magnitude higher, leading to a smaller ratio $R_{s / p}$. The higher seismic energy obtained in Montserrat could be partly explained (i.e., a factor of 2 ) by the fact that all the components of the ground velocity are taken into account.

\subsection{Flow Dynamics and Seismic Energy}

Numerical simulations provide the details of the interaction between the flow and the topography. They also make it possible to calculate the force applied by the flow to the ground that generate seismic waves [Favreau et al., 2010; Moretti et al., 2012, 2015]. Figures 9a-9d present the details of a typical simulation along the Aymer's ghaut profile when using a volume-dependent friction coefficient (6). An initial mass of $V=50,701 \mathrm{~m}^{3}$ (blue area in Figure 9a) with a corresponding friction angle $\delta=23.4^{\circ}$ is released about $4300 \mathrm{~m}$ from the sea shore. The mass accelerates down the slope until it reaches a position where the slope angle $\theta$ is smaller than the friction angle $\delta$, at time $t=10 \mathrm{~s}$ (Figures $9 \mathrm{a}-9 \mathrm{c}$ ). A second acceleration phase starting at $t=15 \mathrm{~s}$ is observed when the mass again reaches a region where $\theta>\delta$ until the maximum velocity is reached at $t=20 \mathrm{~s}$. The mass then slows down as it reaches another portion of the slope with $\theta<\delta$, until it stops. At $36 \mathrm{~s}$, most of the mass has already stopped, while a small fraction of the material is still flowing down until it forms a second bulge $1.2 \mathrm{~km}$ from the initial position (grey area in Figure 9a). The force $F$ that the mass applies to the ground reflects the acceleration/deceleration phases as illustrated in Figure $9 \mathrm{c}$ where the norm of this force $F$ calculated with the SHALTOP model is represented (for details on the force calculation, see Favreau et al. [2010] and Moretti et al. [2012, 2015]). Essentially, the force has a direction opposite to the flow when it accelerates and the same direction than the flow when it decelerates [see, e.g., Zhao et al., 2012]. The direction of the force could be observed on its horizontal component $F_{h}$ represented on Figure 10b. Figures 10a and 10b show $F_{h}$ and the angle of the slope $\alpha_{\text {center }}$ at the position of the center of mass for the simulation shown in Figure 9a. $F_{h}$ decreases with increasing $\alpha_{\text {center }}$. Each time $\alpha_{\text {center }}$ becomes lower than the friction angle (red dashed lines in Figure 10a), $F_{h}$ becomes positive, with a time delay of a few seconds. Thus, the mass decelerates. Conversely, each time $\alpha_{\text {center }}$ becomes higher than the friction angle, $F_{h}$ becomes negative, with a time delay of a few seconds. Thus, the mass accelerates.

Figure $9 \mathrm{~d}$ shows the instantaneous frictional power $W(t)=F \cdot \mathrm{u}$ that was found to be strongly correlated with the seismic power envelope filtered between 0.1 and $0.05 \mathrm{~Hz}$ [Schneider et al., 2010]. One of the objectives is to observe potential correlations with the higher frequency seismic signal.

In the frequency range investigated here $(f>1 \mathrm{~Hz}$ ), it is not possible to invert the seismic signal to determine the force applied by the flow to the ground or to calculate the seismic signal generated by the force $F$ as was done at lower frequencies by Brodsky et al. [2003], Favreau et al. [2010], Moretti et al. [2012], Ekström and Stark [2013], Yamada et al. [2013], Allstadt [2013], and Moretti et al. [2015]. At these frequencies, seismic waves are sensitive to small inhomogeneities within the Earth, which seismic velocity models cannot capture. Another way of comparing the numerical flow model with seismic data in this frequency range is to compare the simulations with the observed seismic power (i.e., seismic energy per second). To do this, we choose an event with a seismic duration close to the flow duration calculated with the model that was located in Aymer's Ghaut. An example is represented in Figures $9 \mathrm{e}$ and $9 \mathrm{f}$, where the seismic duration of the event $t_{\mathrm{s}}=87 \mathrm{~s}$ is close to the flow duration $t_{f}=97 \mathrm{~s}$. The calculated force $F$ correlates well with the seismic power estimated using $1 \mathrm{~s}$ sliding windows. Both exhibit two peaks around $t=3-5 \mathrm{~s}$ and $t=36-40 \mathrm{~s}$. The frictional power is less peaked and less clearly related to the seismic power estimated using sliding windows. Most of the seismic energy ranges within $0-6 \mathrm{~Hz}$. Note that almost no energy is recorded between 6 and $20 \mathrm{~Hz}$ during the first peak, while $25 \%$ of the energy in the second peak is between 6 and $20 \mathrm{~Hz}$.

Qualitatively, the same observations can be made for the 5 times smaller event of Figures $9 \mathrm{~g}-91$. The maximum force (first peak) is 5 times smaller than that calculated in Figure 9c, suggesting that this maximum force is proportional to the volume involved as verified by the third event (Figures $9 m-9 r$ ) and in agreement with Ekström and Stark [2013] and Zhao et al. [2012]. The second peak of the force is much smaller than for the larger event, as is also observed for the seismic power and the frictional power. The force peaks are, however, more correlated over time with those of the seismic power than the frictional power peaks.

The same observations can be made once again for the even smaller simulated rockfall $\left(V=3906 \mathrm{~m}^{3}\right.$ and $\delta=27.8^{\circ}$ ) of Figures $9 \mathrm{~m}$ and $9 \mathrm{n}$. For this simulated rockfall, most of the mass stops upslope in the region 

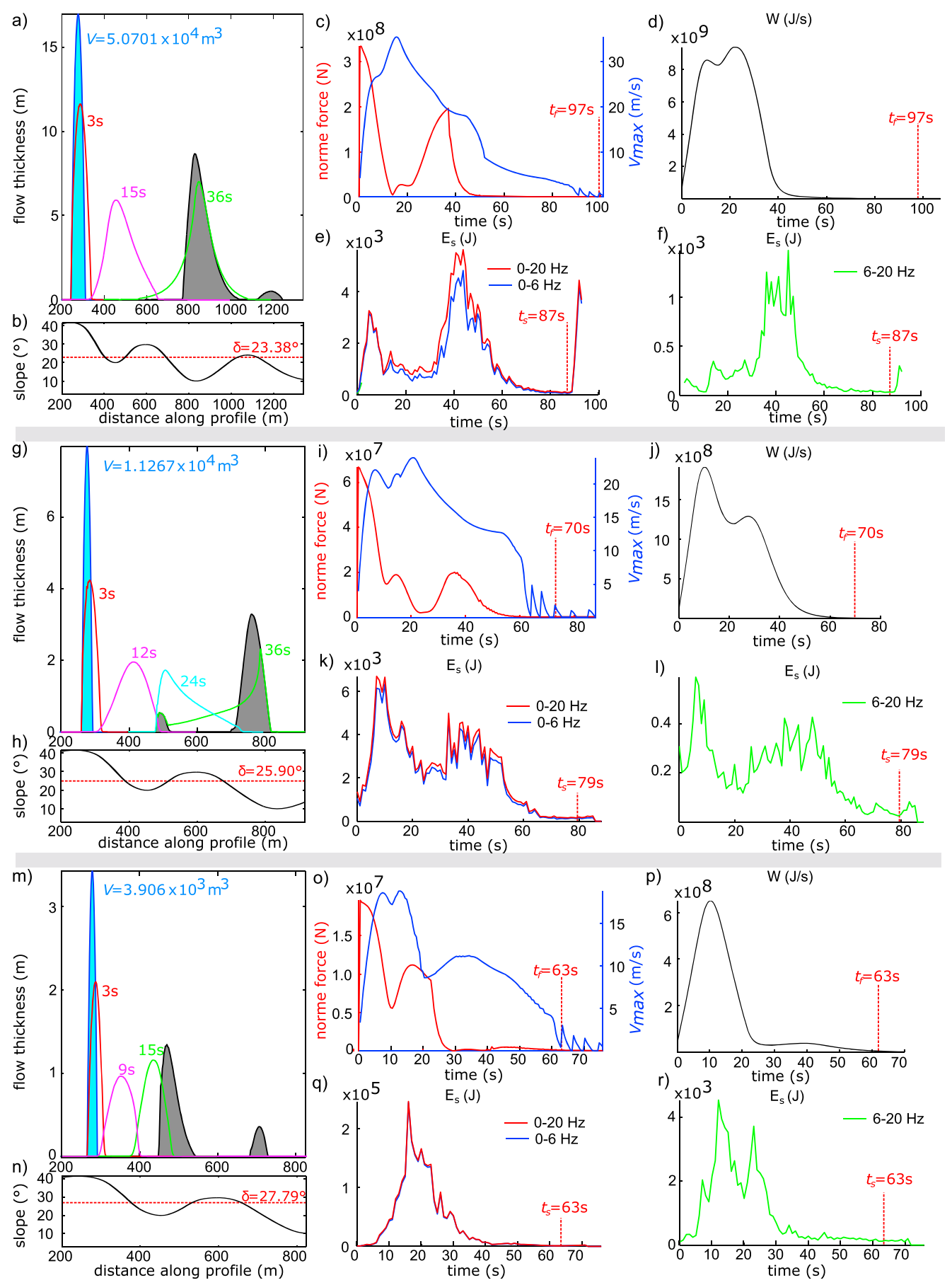

Figure 9. Simulations of granular flow and seismic energy of events located at Aymer's ghaut. (a-d) Outputs of a 2-D simulation of granular flow along the Aymer's ghaut profile, with an initial mass of 50,701 $\mathrm{m}^{3}$ and friction angle $\delta=23.4^{\circ}$. (a) Thickness of the simulated mass above the ground at the initial state (blue mass), at $3 \mathrm{~s}, 15 \mathrm{~s}$, and $36 \mathrm{~s}$ after the start of the simulation and at the end of the simulation (grey mass). (b) Change of the slope angle with the horizontal distance along the profile. (c) Maximum velocity of the simulated mass (blue line) and norm of the basal force applied by the flow to the ground (red line) as a function of time. Simulation end time $t_{f}$ is indicated. (d) The frictional power at the base of the flowing mass (basal force multiplied by the velocity). (e) Seismic energy $E_{s}$ estimated using $1 \mathrm{~s}$ sliding windows of the event of Figure 3 located at Aymer's ghaut. End time $t_{s}$ is indicated. (f) Seismic energy $E_{s}$ estimated using $1 \mathrm{~s}$ sliding windows of the event in Figure 3 for high frequencies only $(6-20 \mathrm{~Hz}) .(\mathrm{g}-\mathrm{j})$ outputs of a 2-D simulation of granular flow along the Aymer's ghaut profile, with an initial mass of $11,267 \mathrm{~m}^{3}$ and friction angle $\delta=25.9^{\circ}$. (k, l) Same as Figures $9 e$ and $9 f$ for an event located at Aymer's ghaut. $(m-p)$ Outputs of a 2-D simulation of granular flow along the Aymer's ghaut profile, with an initial mass of $4 \times 10^{3} \mathrm{~m}^{3}$ and friction angle $\delta=25.9^{\circ}$. (q, r) Same as Figures $9 \mathrm{e}$ and $9 \mathrm{f}$ for another event located at Aymer's ghaut. Note the exaggeration of the vertical axis in Figures 9a, $9 \mathrm{~g}$, and $9 \mathrm{~m}$. 
a)

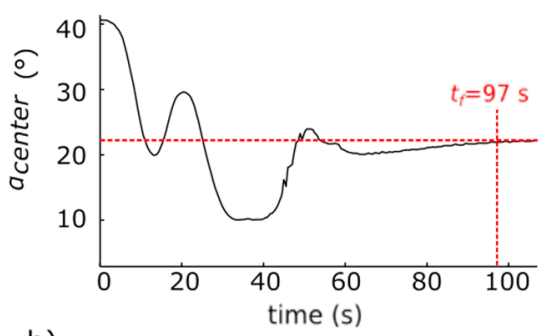

b)

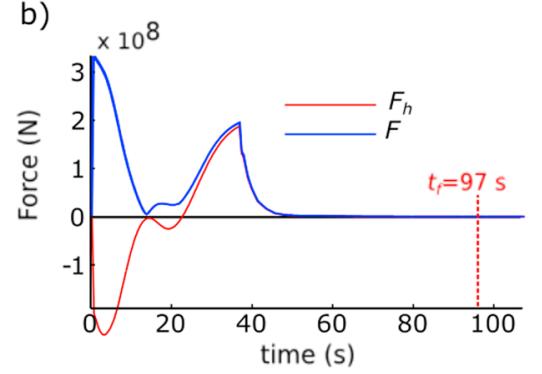

c)

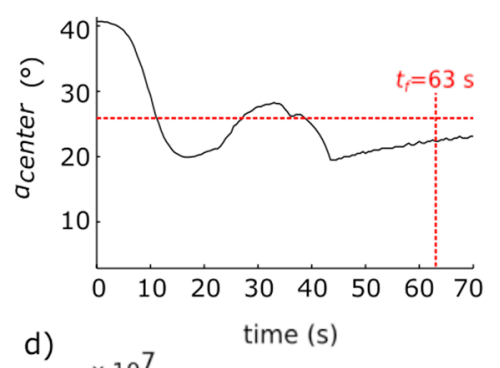

d)



Figure 10. Simulations of granular flows at Aymer's ghaut. (a) Angle of the slope $\alpha_{\text {center }}$ at the position of the center of mass for the simulation of Figure $9 a$. The horizontal red line indicates the value of the friction angle $\delta$. The vertical red line indicates the time $t_{f}$, i.e., the sliding duration. (b) The horizontal component $F_{h}$ and the norm of the basal force $F$ applied by the flow to the ground as a function of time for the simulation of Figure 9a. (c and d) Same as Figures 10a and $10 b$ for the simulation of Figure $9 q$.

where $\theta<\delta$ for the first time (see Figures 9m and 9n). A small portion of the mass is able to propagate farther down toward a new zone where $\theta>\delta$ and then stops when $\theta<\delta$ again. The second velocity peak observed in Figure 90 is likely related to the acceleration of this small propagating mass. A small force and frictional power are associated with this motion for $t_{f}>40 \mathrm{~s}$. Similarly, low seismic power is also observed for $t_{s}>40 \mathrm{~s}$ supporting a very strong correlation between the seismic power and the accelerations/decelerations of the flowing mass. Figures $10 \mathrm{c}$ and $10 \mathrm{~d}$ show the angle of the slope $\alpha_{\text {center }}$ at the position of the center of mass and the horizontal component of the basal force $F_{h}$, respectively, for the simulation shown in Figure $9 \mathrm{k} . F_{h}$ decreases with increasing $\alpha_{\text {center }}$. Each time $\alpha_{\text {center }}$ becomes lower (higher) than the friction angle (red dashed lines in Figure 10c), $F_{h}$ becomes positive (negative), with a time delay of a few seconds. Thus, the mass decelerates.

Note that the two force peaks for the small event of Figures $9 \mathrm{~m}$ and $9 \mathrm{n}$ are not as well pronounced as for the larger events (Figures $9 \mathrm{a}$ and $9 \mathrm{~g}$ ) and that the frictional power exhibits only one peak. Interestingly, the seismic power between 0 and $6 \mathrm{~Hz}$ exhibits one peak while two peaks are observed at higher frequencies (Figure 9r). The peaks in the seismic power are, however, not well in phase with those of the force and here the frictional power correlates slightly better with the seismic power.

For most of the events located in Aymer's ghaut, the simulated basal force and the frictional power correlate very well with the seismic power at $f>1 \mathrm{~Hz}$ for flows with $t_{f} \simeq t_{s}$. Only four seismic events were poorly correlated with the simulations, two of them being mixed with other seismic sources.

Very similar seismic signals and flow dynamics are observed for the events located in Gages ghaut (Figure 11), also exhibiting a strong correlation between force $F$, frictional power, and seismic power. Two simulations along the profile of Gages ghaut (flow thickness, velocity, force applied to the ground, and frictional power) and two seismic events (seismic power), located at Gages ghaut, of similar durations $\left(t_{f} \simeq t_{s}\right)$ are compared. The simulations are performed with a friction coefficient that decreases with the volume (equation (6)). As for most simulations in Aymer's ghaut, the force $F_{h}$ reflects the acceleration and deceleration of the flow when it reaches slope angles larger and smaller than the friction angle, respectively (see Figures $11 \mathrm{~b}$ and $11 \mathrm{~h}$ ). The forces exhibit two peaks that correlate with the peaks observed for the seismic power estimated sliding windows for seismic events of the same duration as the flow duration (see Figures $11 \mathrm{e}$ and $11 \mathrm{f}$, and $11 \mathrm{k}$ and 111$)$. 

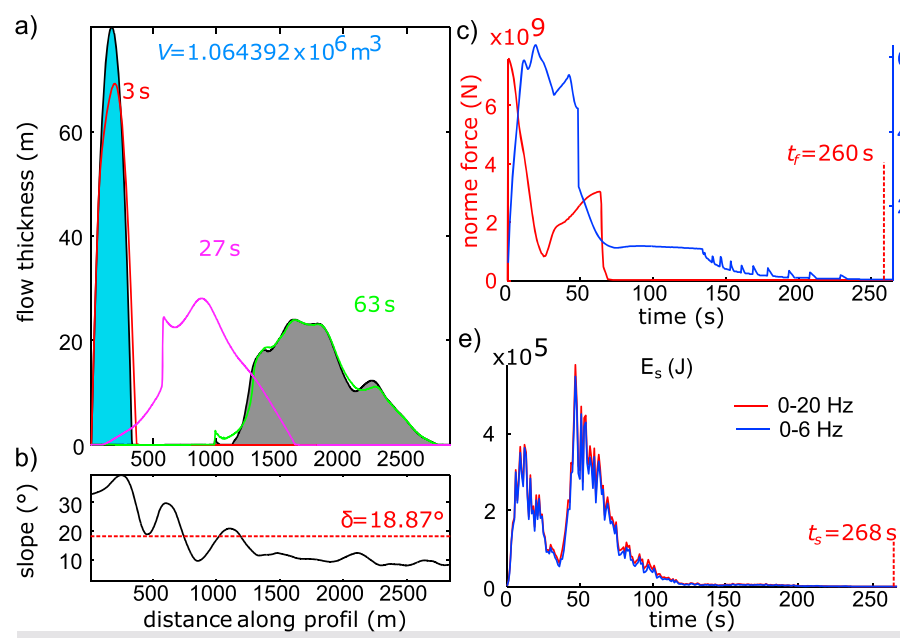

d)
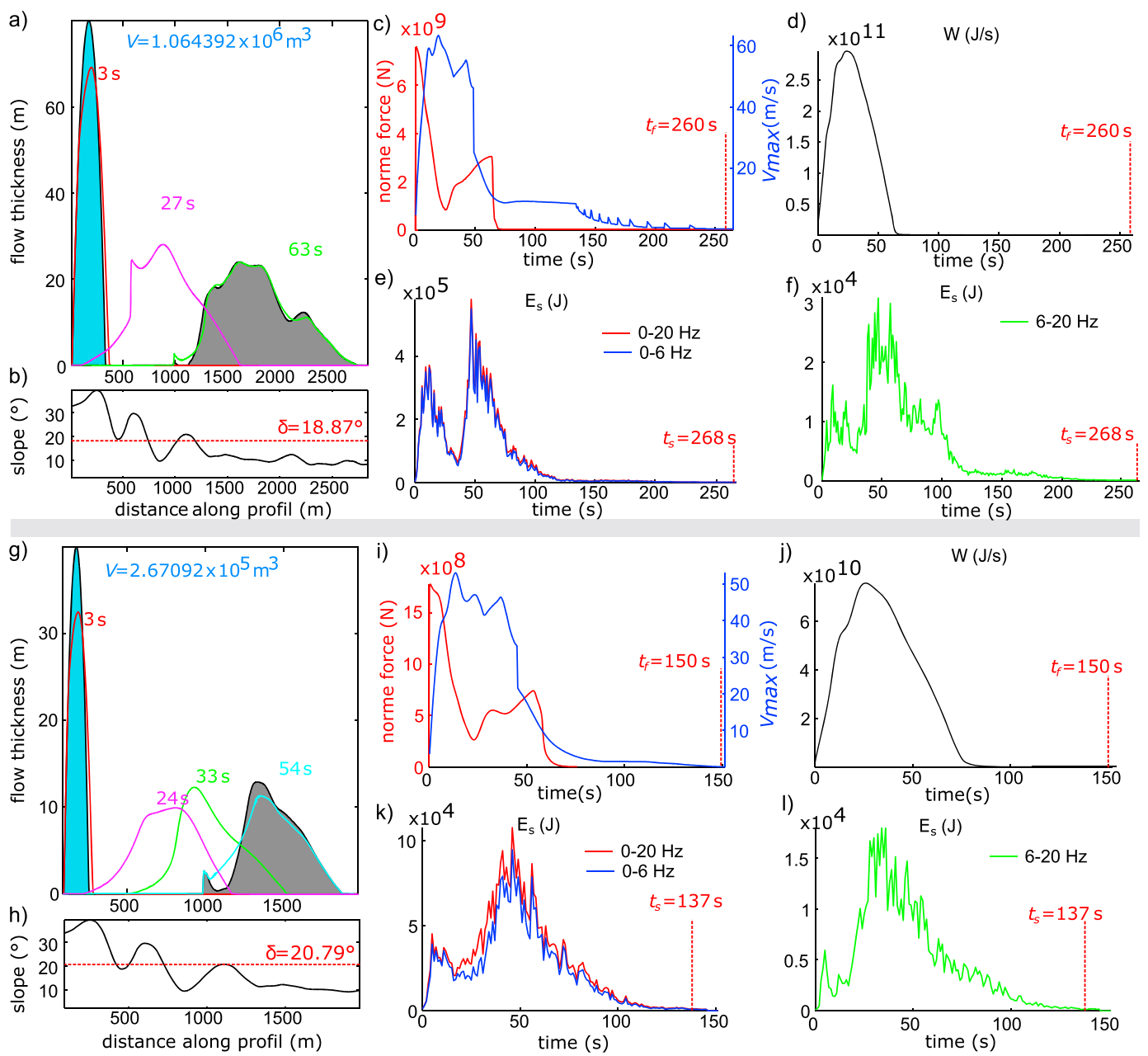

Figure 11. Simulations of granular flow and seismic energy of events located at Gages ghaut.(a-d) Outputs of a 2-D simulation of granular flow along the Gages ghaut profile, with an initial mass of 1,064,392 $\mathrm{m}^{3}$ and friction angle $\delta=18.9^{\circ}$. (a) Thickness of the simulated mass above the ground, at $t=0 \mathrm{~s}$ (blue mass), $3 \mathrm{~s}, 27 \mathrm{~s}$, and $63 \mathrm{~s}$ and at the end of the simulation (grey deposit). (b) Change of the slope angle with the horizontal distance along the profile. (c) Maximum velocity of the simulated mass (blue line) and norm of the basal force applied by the flowing mass to the ground (red line) as a function of time. Simulation end time $t_{f}$ is indicated. (d) The frictional flow rate (the basal force multiplied by the velocity). (e) Seismic energy $E_{s \text { freq }}$ estimated $1 \mathrm{~s}$ sliding windows for an event located in Gages ghaut. End time $t_{s}$ is indicated. (f) Seismic energy $E_{s \text { freq }}$ for the same event for high frequencies only $(6-20 \mathrm{~Hz})$. (g-j) Outputs of a 2-D simulation of granular flow along the Gages ghaut profile, with an initial mass of $267,092 \mathrm{~m}^{3}$ and friction angle $\delta=20.8^{\circ}$. (k, l) Same as Figures $11 \mathrm{e}$ and $11 \mathrm{f}$ for another event located at Gages ghaut. Note the exaggeration of the vertical axis of Figures $11 \mathrm{a}$ and $11 \mathrm{~g}$.

\section{Conclusion}

Using 200 records of granular and pyroclastic flows at the Soufrière Hills Volcano (Montserrat Island), we have shown that the seismic energy $E_{s}$ follows a power law $E_{s} \propto t_{s}^{\beta_{s}}$, where $t_{s}$ is the seismic event duration. Using numerical simulations of these flows, we have shown that a similar power law is observed for the loss of potential energy $\Delta E_{p} \propto t_{f}^{\beta_{p}}$, where $t_{f}$ is the numerical flow duration. The coefficients are very similar, i.e., $\beta_{s} \simeq \beta_{p} \simeq 2.4 \pm 1$ and are shown to mostly depend on the topography where the granular mass flows. These two power laws have very similar scattering. As $t_{s} \simeq t_{f}$, these strong similarities between the power laws suggest that the ratio of the seismic energy to the loss of potential energy $R_{s / p}$ is almost constant, as observed for rockfalls at Piton de la Fournaise. Here $R_{s / p} \simeq 10^{-5}$, corresponding to the smallest ratios observed by Hibert et al. [2011] and Deparis et al. [2008], possibly due to the larger source-station distances in our case. These power laws, observed both at Montserrat and Reunion Island, make it possible to calculate the 
conversion of potential to seismic energy. Given that they seem to hold in these very different contexts, they may possibly apply more generally.

Despite the low efficiency of the potential to seismic energy conversion, numerical simulation of the flows shows that the seismic energy correlates well with the force applied by the granular flow to the ground. In particular, we show that the peaks in seismic power can be explained by the interaction of the flow with the topography that generate phases of acceleration/deceleration of the granular mass related to the relative values of the slope angle and the friction angle of the material involved. While the link between the seismic signal and the flow dynamics has been widely demonstrated at low frequencies $(f<0.1 \mathrm{~Hz})$, our results obtained with high-frequency data $(f>1 \mathrm{~Hz})$ suggest that information on the change of the force applied by the flow to the ground with time can be obtained by analysis of the high-frequency seismic power. As a result, numerical models of natural granular flows can also be constrained by comparing the calculated force with the high-frequency seismic power over time.

Note that the similarity in the power laws and the correlation between the flow dynamics and the seismic energy could only be found when using a friction coefficient in the granular flow model that decreased with the volume of the released mass. Indeed, using a constant friction coefficient for all rockfalls and pyroclastic flows makes it impossible to determine the duration of small to large events or their runout distances. The difference between the simulated results using a constant friction coefficient and the seismic data may result from physical processes that are not taken into account in the model such as erosion processes and to the approximations made in the thin-layer depth-averaged model used here. However, the very good agreement between the simulation and seismic data using a volume-dependent friction coefficient derived from completely different data (data on the deposits of a wide range of small to large landslides in different geological context) supports the hypothesis that these seismic data may carry the signature of this friction weakening effect. This is the first time that analysis of seismic data suggests that a friction coefficient depending on the volume can be used to simulate granular flows with volumes spanning between 500 and $10^{6} \mathrm{~m}^{3}$, such as those observed in Montserrat. More precisely, the empirical volume-dependent friction coefficient proposed by Lucas et al. [2014] is found to reproduce well the seismic power laws and the signature of the flow dynamics on the seismic energy power. As a result, the friction coefficient varies here within the range $0.34<\mu<0.62$ (i.e., $18^{\circ}<\delta<32^{\circ}$ ) for volumes of $500<V<10^{6} \mathrm{~m}^{3}$.

The small values of the friction coefficient needed to reproduce large pyroclastic flows in Montserrat and more generally large landslides worldwide is in agreement with previous studies [Mangeney et al., 2000; Heinrich et al., 2001; Bayarri et al., 2009; Nikolkina et al., 2011; Pirulli et al., 2007; Lucas et al., 2014]. As shown by Lucas et al. [2014], the friction weakening with volume can be the result of a friction decrease with velocity or other dynamic parameters as also suggested for earthquakes. Defining friction weakening in landslides more precisely is one of the most important challenges in the domain, and we show here that high-frequency seismic data may provide an ideal tool to go farther in this direction.

\section{Appendix A: An Attenuation Model}

We used the seismic records of the rockfalls that could be located to estimate the attenuation factor $\alpha$ as a function of the frequency. Indeed, the amplitude $A$ of seismic records decreases with increasing distance $r$ to the source according to the following equation: $A \propto r^{-n} e^{-\alpha r}$, with $n=0.5$ for surface waves and $n=1$ for body waves (consistently with the geometrical spreading of these waves). The linear relationship derived by Kanai et al. [1984] follows from this property:

$$
\log _{e}\left[\frac{a_{1}}{a_{2}}\left({\frac{\Delta_{1}}{\Delta_{2}}}^{n}\right)\right]=\log _{e}\left(\frac{\gamma_{1}}{\gamma_{2}}\right)-\alpha\left(\Delta_{1}-\Delta_{2}\right)
$$

with $a_{1}$ and $a_{2}$ the maximum amplitudes at two stations, $\Delta_{1}$ and $\Delta_{2}$ the corresponding epicentral distances, and $\gamma_{1}$ and $\gamma_{2}$ constants relating to the ground and installation conditions of each sensor.

The slope $\alpha$ of the linear relationship is estimated at various frequencies using the filtered seismic signals of all the located rockfalls, for all station pairs. The signals are filtered several times between 0.5 and $19.5 \mathrm{~Hz}$ using $1 \mathrm{~Hz}$ band-pass filters. As the seismic source is complex, the maximum amplitudes $a_{1}$ and $a_{2}$ are selected within the first $20 \mathrm{~s}$ of the filtered signals. Figure A1 presents the corresponding point clouds for $n=0.5$ and $n=1$ at $4.5-5.5 \mathrm{~Hz}$. The linear fit of the point clouds gives an estimation of $\alpha$ at $5 \mathrm{~Hz}$ when considering that the signal is dominated by body waves $(n=1)$ or by surface waves $(n=0.5)$. For all frequency bands, the 
a)

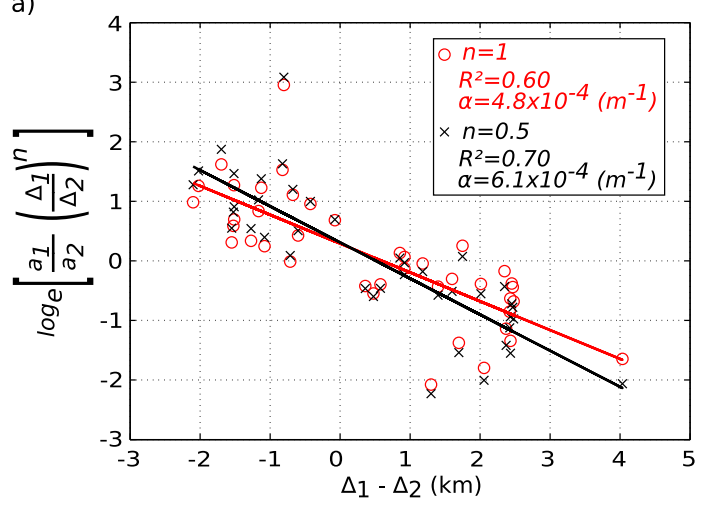

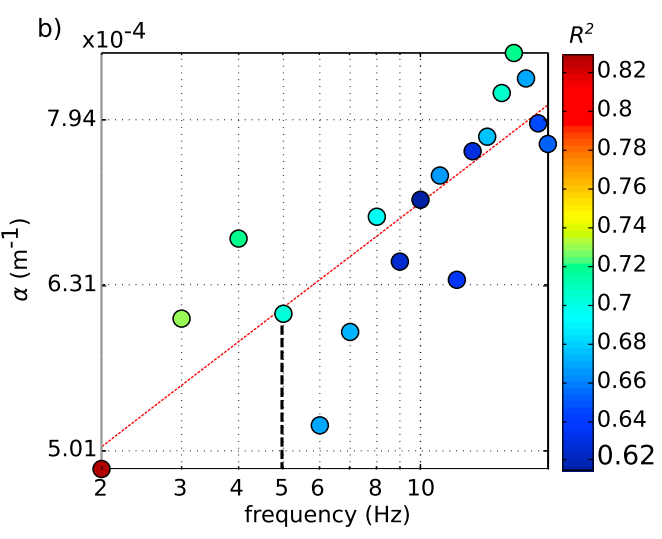

Figure A1. Estimation of the attenuation of high frequencies at the Soufrière Hills Volcano.(a) Estimation of the attenuation at $5 \mathrm{~Hz}$ using the linear relationship of Kanai et al. [1984]. (b) Estimation of the attenuation assuming that the seismic signal of rockfalls is mostly composed of surface waves $(n=0.5)$.

linear regressions have higher corresponding $R^{2}$ statistics when considering that the signal is dominated by surface waves $(n=0.5$ ). This result is in agreement with our assumption that the seismic signal of rockfalls is mostly made of surface waves. An empirical curve of the evolution of $\alpha$ with frequency is deduced for $n=0.5$ (Figure A1).

If we assume that the quality factor $Q$ is frequency dependent and that $Q(f)=Q_{o} f^{n}$, with $n \in[01]$ [Erickson et al., 2004; Campbell, 2009], then $\alpha$ would vary with frequency given the following expression: $\alpha=\frac{\pi}{Q_{0} c} f^{1-n}$. Our results indicate a possible value of $Q_{0}$ that is very small $\left(Q_{0}<50\right.$ and $Q_{0} \approx 10$ if we consider $\left.c=1300 \mathrm{~m} / \mathrm{s}\right)$, consistent with the estimation made by Jolly et al. [2002] for the Soufrière Hills Volcano.

The attenuation $\alpha$ is used to compute the seismic energy $E_{s}$ at each frequency. Figure A2 shows the estimation of $E_{s \text { freq }}$ (solid lines) and of the integrated seismic energy $\int_{f_{1}}^{f_{x}} E_{s}(f) d f$ (dashed lines) at each frequency for an event located in Aymer's ghaut (see Figures 1 and 3 of the article) and for signals recorded at stations MBFR, MBLY, MBWH, MBGB, and MBGH. Even if a correction is applied to take the attenuation $\alpha$ into account, the energy at high frequency is somewhat less for station MBFR compared to station MBLY. As a result, the seismic energy calculated from the seismic signal at MBFR is about $20 \%$ smaller than that calculated from the signal
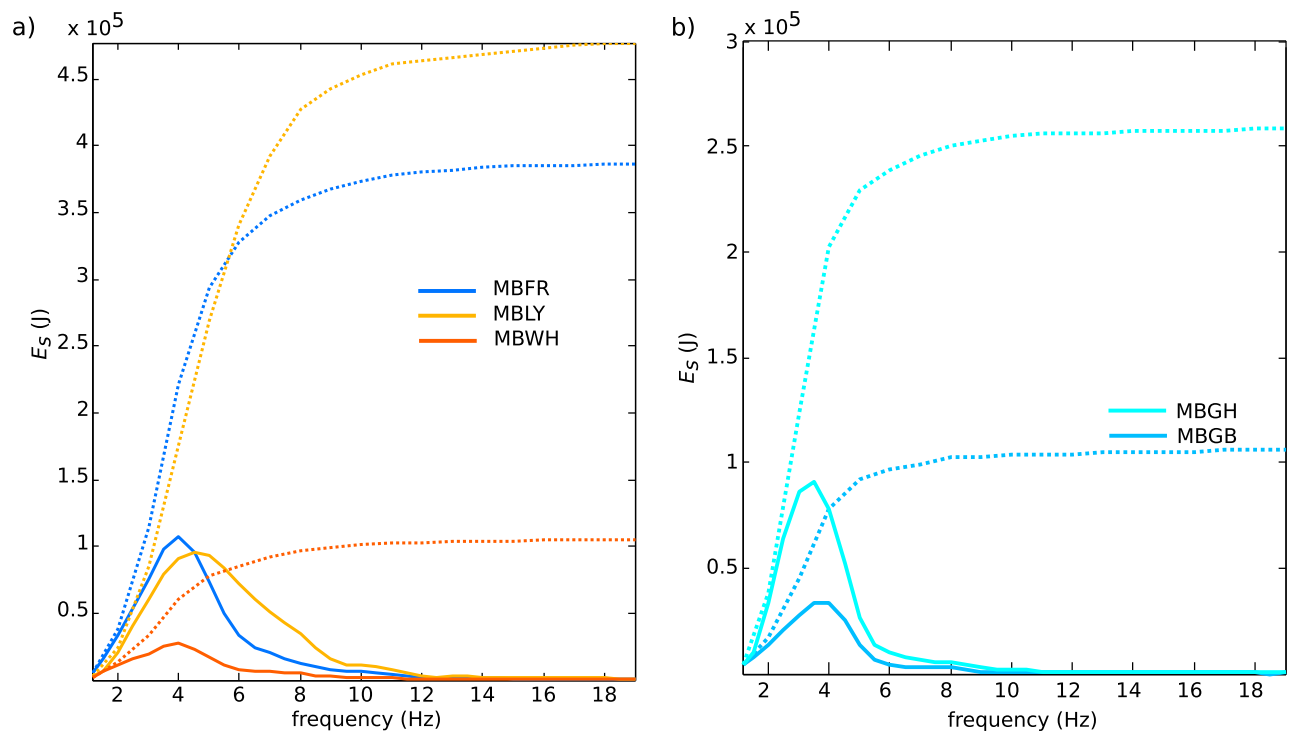

Figure A2. Frequency-dependent $E_{s}$. (a) The seismic energy $E_{s}$ estimated at different frequencies for stations MBFR, MBLY, and MBWH (at distances of 2.0, 2.2, and $3.9 \mathrm{~km}$ from the source area, respectively) for the event presented in Figures 1 and 3 (solid lines) and the integrated seismic energy $\int_{f_{1}}^{f_{x}} E_{s}(f) d f$ (dashed lines). (b) Ditto for stations MBGB and $\mathrm{MBGH}$ at distances of 6.0 and $3.7 \mathrm{~km}$ from the source area. 


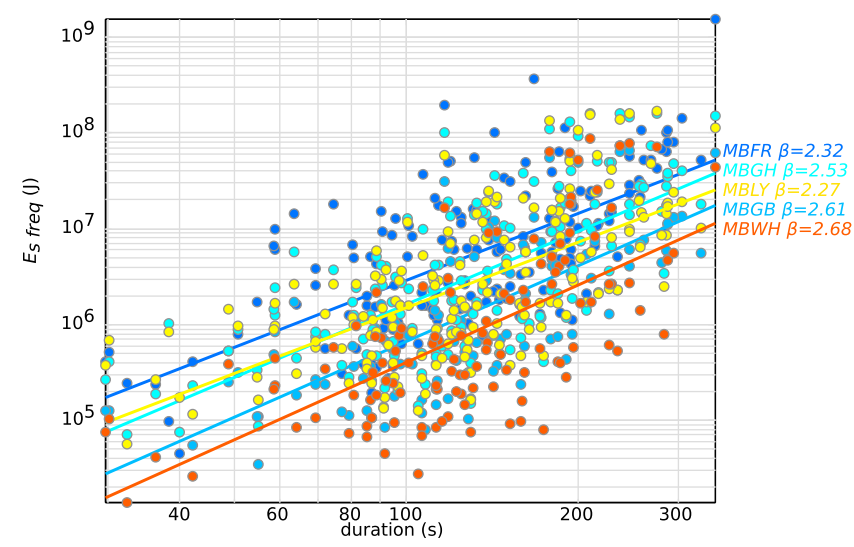

Figure A3. The seismic energy $E_{s f r e q}$ as a function of the signal duration $t_{s}$ for different stations. $E_{s \text { freq }}$ is estimated for stations MBFR, MBGH, MBLY, MBGB, and MBWH at distances of 2.0, 3.7, 2.2, 6.0, and $3.9 \mathrm{~km}$ from the source area, respectively. The power law $E_{s} \propto t_{s}^{\beta}$ is fitted for each station (solid lines) and the associated $\beta$ values are indicated on the plot.

at MBLY, even though the source-station distances are almost the same. This could be due to site effects or to the different path of the waves. In the paper, we averaged $E_{s}$ for all stations in order to average discrepancies due to the changes of frequency content related to different seismic paths or site effects. Figure $A 3$ represents the dispersion of the estimation of the seismic energy as a function of the signal duration $t_{s}$ for stations MBFR, MBGH, MBLY, MBGB, and MBWH. This shows that the average seismic energy at more distant stations is lower, even when taking attenuation into account. At depths inferior to $500 \mathrm{~m}$, the frequency response of the soil is highly nonlinear. Our homogenous model for attenuation is too simple to reproduce such phenomena, as well as path effects due to lateral variations of the ground. Both effects will partly explain the dispersion of the estimation of the seismic energy for the various seismic stations. The impact of these effects increases with distance.

\section{Acknowledgments}

The research was funded by Institut de Physique du Globe de Paris, the French ANR LANDQUAKES and SYNAPS@ programmes, and by the ERC Consolidator SLIDEQUAKES grant. Classified seismic data were provided by the Montserrat Volcano Observatory. The numerical model SHALOP is being developed by the Institut de Physique du Globe.

\section{References}

Aki, K., and P. G. Richards (1980), Quantitative Seismology, vol. 1424, Freeman, San Francisco, Calif.

Allstadt, K. (2013), Extracting source characteristics and dynamics of the August 2010 mount meager landslide from broadband seismograms, J. Geophys. Res. Earth Surf., 118(3), 1472-1490, doi:10.1002/jgrf.20110.

Baillard, C., W. C. Crawford, V. Ballu, C. Hibert, and A. Mangeney (2013), An automatic kurtosis-based p-and s-phase picker designed for local seismic networks, Bull. Seismol. Soc. Am., 104, 394-409.

Bates, D. M., and D. G. Watts (1988), Nonlinear Regression Analysis and Its Applications, John Wiley, New York.

Bayarri, M., J. O. Berger, E. S. Calder, K. Dalbey, S. Lunagomez, A. K. Patra, E. B. Pitman, E. T. Spiller, and R. L. Wolpert (2009), Using statistical and computer models to quantify volcanic hazards, Technometrics, 51(4), 402-413.

Berrocal, J., A. Espinosa, and J. Galdos (1978), Seismological and geological aspects of the Mantaro landslide in Peru, Nature, 275(5680), 533-536.

Bonnefoy-Claudet, S., F. Cotton, and P.-Y. Bard (2006), The nature of noise wavefield and its applications for site effects studies: A literature review, Earth Sci. Rev., 79(3), 205-227.

Bouchut, F., and M. Westdickenberg (2004), Gravity driven shallow water models for arbitrary topography, Commun. Math. Sci., 2(3), 359-389.

Bouchut, F., A. Mangeney-Castelnau, B. Perthame, and J.-P. Vilotte (2003), A new model of Saint Venant and savage-hutter type for gravity driven shallow water flows, C. R. Mathematique, 336(6), 531-536.

Brodsky, E. E., E. Gordeev, and H. Kanamori (2003), Landslide basal friction as measured by seismic waves, Geophys. Res. Lett., 30(24), 2236, doi:10.1029/2003GL018485.

Campbell, K. W. (2009), Estimates of shear-wave q and $\kappa 0$ for unconsolidated and semiconsolidated sediments in eastern North America, Bull. Seismol. Soc. Am., 99(4), 2365-2392.

Dade, W. B., and H. E. Huppert (1998), Long-runout rockfalls, Geology, 26(9), 803-806.

Dahlen, F. (1993), Single-force representation of shallow landslide sources, Bull. Seismol. Soc. Am., 83(1), $130-143$.

Dammeier, F., J. R. Moore, F. Haslinger, and S. Loew (2011), Characterization of Alpine rockslides using statistical analysis of seismic signals, J. Geophys. Res., 116, F04024, doi:10.1029/2011JF002037.

Davies, T. R. (1982), Spreading of rock avalanche debris by mechanical fluidization, Rock Mech., 15(1), 9-24.

Deparis, J., D. Jongmans, F. Cotton, L. Baillet, F. Thouvenot, and D. Hantz (2008), Analysis of rock-fall and rock-fall avalanche seismograms in the French Alps, Bull. Seismol. Soc. Am., 98(4), 1781-1796.

Deplus, C., A. Le Friant, G. Boudon, J.-C. Komorowski, B. Villemant, C. Harford, J. Ségoufin, and J.-L. Cheminée (2001), Submarine evidence for large-scale debris avalanches in the Lesser Antilles arc, Earth Planet. Sci. Lett., 192(2), 145-157.

Eissler, H. K., and H. Kanamori (1987), A single-force model for the 1975 Kalapana, Hawaii, earthquake, J. Geophys. Res., 92(B6), $4827-4836$. Ekström, G., and C. P. Stark (2013), Simple scaling of catastrophic landslide dynamics, Science, 339(6126), 1416-1419.

Erickson, D., D. E. McNamara, and H. M. Benz (2004), Frequency-dependent Ig q within the continental United States, Bull. Seismol. Soc. Am., 94(5), 1630-1643. 
Farin, M., A. Mangeney, and O. Roche (2014), Fundamental changes of granular flow dynamics, deposition, and erosion processes at high slope angles: Insights from laboratory experiments, J. Geophys. Res. Earth Surf., 119(3), 504-532, doi:10.1002/2013JF002750.

Favreau, P., A. Mangeney, A. Lucas, G. Crosta, and F. Bouchut (2010), Numerical modeling of landquakes, Geophys. Res. Lett., 37, L15305, doi:10.1029/2010GL043512.

Feuillet, N., I. Manighetti, P. Tapponnier, and E. Jacques (2002), Arc parallel extension and localization of volcanic complexes in Quadeloupe, Lesser Antilles, J. Geophys. Res., 107(B12), 2331, doi:10.1029/2001JB000308.

Gibbons, J. (1985), Nonparametric Statistical Inference, 2nd ed., M. Dekker, New York.

Harford, C., M. Pringle, R. Sparks, and S. Young (2002), The volcanic evolution of Montserrat using ${ }^{40} \mathrm{Ar} /{ }^{39} \mathrm{Ar}$ geochronology, in The Eruption of Soufrière Hills Volcano, Montserrat, from 1995 to 1999, vol. 21, edited by T. H. Druitt and B. P. Kokelaar, pp. 93-113, London.

Heim, A. (1932), Bergsturz und Menschenleben, Fretz and Wasmuth, Indiana Univ.

Heinrich, P., G. Boudon, J. Komorowski, R. Sparks, R. Herd, and B. Voight (2001), Numerical simulation of the December 1997 debris avalanche in Montserrat, Lesser Antilles, Geophys. Res. Lett., 28(13), 2529-2532.

Helmstetter, A., and S. Garambois (2010), Seismic monitoring of Séchilienne rockslide (French Alps): Analysis of seismic signals and their correlation with rainfalls, J. Geophys. Res., 115, F03016, doi:10.1029/2009JF001532.

Hibert, C., A. Mangeney, G. Grandjean, and N. Shapiro (2011), Slope instabilities in Dolomieu crater, Réunion Island: From seismic signals to rockfall characteristics, J. Geophys. Res., 116, F04032, doi:10.1029/2011JF002038.

Hibert, C., G. Ekström, and C. P. Stark (2014a), Dynamics of the Bingham canyon mine landslides from seismic signal analysis, Geophys. Res. Lett., 41, 4535-4541, doi:10.1002/2014GL060592.

Hibert, C., et al. (2014b), Automated identification, location, and volume estimation of rockfalls at Piton de la Fournaise volcano, J. Geophys. Res. Earth Surf., 119, 1082-1105, doi:10.1002/2013JF002970.

Izutani, Y., and H. Kanamori (2001), Scale-dependence of seismic energy-to-moment ratio for strike-slip earthquakes in Japan, Geophys. Res. Lett., 28(20), 4007-4010.

Jolly, A., G. Thompson, and G. Norton (2002), Locating pyroclastic flows on Soufriere Hills Volcano, Montserrat, West Indies, using amplitude signals from high dynamic range instruments, J. Volcanol. Geotherm. Res., 118(3), 299-317.

Kanai, K., K. Yamabe, and A. Habasaki (1984), Study of the attenuation of seismic waves, in Proceedings of the Eighth World Conference on Earthquake Engineering, vol. 2, pp. 273-280, Prentice-Hall, San Francisco, Calif.

Kanamori, H. (1977), The energy release in great earthquakes, J. Geophys. Res., 82(20), 2981-2987.

Kanamori, H., and J. W. Given (1982), Analysis of long-period seismic waves excited by the May 18, 1980, eruption of Mount St. Helens -A terrestrial monopole?, J. Geophys. Res., 87(B7), 5422-5432.

Kokelaar, B. (2002), Setting, chronology and consequences of the eruption of Soufrière Hills Volcano, Montserrat (1995-1999), in The Eruption of Soufrière Hills Volcano, Montserrat From 1995 to 1999, vol. 21, pp. 1-43, Geol. Soc. Mem., London.

Kuo, C., Y. Tai, F. Bouchut, A. Mangeney, M. Pelanti, R. Chen, and K. Chang (2009), Simulation of Tsaoling landslide, Taiwan, based on Saint Venant equations over general topography, Eng. Geol., 104(3), 181-189.

Lacroix, P., and A. Helmstetter (2011), Location of seismic signals associated with microearthquakes and rockfalls on the Séchilienne Landslide, French Alps, Bull. Seismol. Soc. Am., 101(1), 341-353.

Langer, H., S. Falsaperla, T. Powell, and G. Thompson (2006), Automatic classification and a-posteriori analysis of seismic event identification at Soufrière Hills Volcano, Montserrat, J. Volcanol. Geotherm. Res., 153(1), 1-10.

Lay, T., and T. C. Wallace (1995), Modern Global Seismology, vol. 58, Academic Press, San Diego, Calif.

Le Friant, A., C. Harford, C. Deplus, G. Boudon, R. Sparks, R. Herd, and J. Komorowski (2004), Geomorphological evolution of Montserrat (West Indies): Importance of flank collapse and erosional processes, J. Geol. Soc., 161(1), 147-160.

Le Friant, A., E. Lock, M. Hart, G. Boudon, R. Sparks, M. Leng, C. W. Smart, J.-C. Komorowski, C. Deplus, and J. Fisher (2008), Late pleistocene tephrochronology of marine sediments adjacent to Montserrat, Lesser Antilles volcanic arc, J. Geol. Soc., 165(1), 279-289.

Le Friant, A., C. Deplus, G. Boudon, R. Sparks, J. Trofimovs, and P. Talling (2009), Submarine deposition of volcaniclastic material from the 1995-2005 eruptions of Soufrière Hills Volcano, Montserrat, J. Geol. Soc., 166(1), 171-182.

Legros, F. (2002), The mobility of long-runout landslides, Eng. Geol., 63(3), 301-331.

Loughlin, S., R. Luckett, G. Ryan, T. Christopher, V. Hards, S. De Angelis, L. Jones, and M. Strutt (2010), An overview of lava dome evolution, dome collapse and cyclicity at Soufrière Hills Volcano, Montserrat, 2005-2007, Geophys. Res. Lett., 37, L00E16, doi:10.1029/2010GL042547.

Lube, G., H. E. Huppert, R. S. J. Sparks, and M. A. Hallworth (2004), Axisymmetric collapses of granular columns, J. Fluid Mech., 508, 175-199.

Lucas, A., and A. Mangeney (2007), Mobility and topographic effects for large Valles Marineris landslides on Mars, Geophys. Res. Lett., 34, L10201, doi:10.1029/2007GL029835.

Lucas, A., A. Mangeney, D. Mège, and F. Bouchut (2011), Influence of the scar geometry on landslide dynamics and deposits: Application to Martian landslides, J. Geophys. Res., 116, E10001, doi:10.1029/2011JE003803.

Lucas, A., A. Mangeney, and J. P. Ampuero (2014), Frictional velocity-weakening in landslides on Earth and on other planetary bodies, Nat. Commun., 5, 3417, doi:10.1038/ncomms4417.

Mangeney, A., P. Heinrich, R. Roche, G. Boudon, and J. Cheminée (2000), Modeling of debris avalanche and generated water waves: Application to real and potential events in Montserrat, Phys. Chem. Earth Part A, 25(9), 741-745.

Mangeney, A., L. Tsimring, D. Volfson, I. Aranson, and F. Bouchut (2007), Avalanche mobility induced by the presence of an erodible bed and associated entrainment, Geophys. Res. Lett., 34, L22401, doi:10.1029/2007GL031348.

Mangeney, A., O. Roche, O. Hungr, N. Mangold, G. Faccanoni, and A. Lucas (2010), Erosion and mobility in granular collapse over sloping beds, J. Geophys. Res., 115, F03040, doi:10.1029/2009JF001462.

Mangeney-Castelnau, A., F. Bouchut, J. Vilotte, E. Lajeunesse, A. Aubertin, and M. Pirulli (2005), On the use of Saint Venant equations to simulate the spreading of a granular mass, J. Geophys. Res., 110, B09103, doi:10.1029/2004JB003161.

Mangold, N., A. Mangeney, V. Migeon, V. Ansan, A. Lucas, D. Baratoux, and F. Bouchut (2010), Sinuous gullies on Mars: Frequency, distribution, and implications for flow properties, J. Geophys. Res., 115, E11001, doi:10.1029/2009JE003540.

Miller, A., R. Stewart, R. White, R. Luckett, B. Baptie, W. Aspinall, J. Latchman, L. Lynch, and B. Voight (1998), Seismicity associated with dome growth and collapse at the Soufriere Hills Volcano, Montserrat, Geophys. Res. Lett., 25(18), 3401-3404.

Moretti, L., A. Mangeney, Y. Capdeville, E. Stutzmann, C. Huggel, D. Schneider, and F. Bouchut (2012), Numerical modeling of the Mount Steller landslide flow history and of the generated long period seismic waves, Geophys. Res. Lett., 39, L16402, doi:10.1029/2012GL052511.

Moretti, L., K. Allstadt, A. Mangeney, Y. Capdeville, E. Stutzmann, and F. Bouchut (2015), Numerical modeling of the mount meager landslide constrained by its force history derived from seismic data, J. Geophys. Res. Solid Earth, 120, 2579-2599, doi:10.1002/2014JB011426.

Nikolkina, I., N. Zahibo, T. Talipova, and E. Pelinovsky (2011), Pyroclastic flow from Soufrière Hills Volcano, Montserrat: Solid block model, Int. J. Geosci., 2(3), 326-335. 
Norris, R. D. (1994), Seismicity of rockfalls and avalanches at three cascade range volcanoes: Implications for seismic detection of hazardous mass movements, Bull. Seismol. Soc. Am., 84(6), 1925-1939.

Pirulli, M., M.-O. Bristeau, A. Mangeney, and C. Scavia (2007), The effect of the Earth pressure coefficients on the runout of granular material, Environ. Model. Software, 22(10), 1437-1454.

Pouliquen, O. (1999), Scaling laws in granular flows down rough inclined planes, Phys. Fluids, 11(3), 542-548.

Pousse, G., L. F. Bonilla, F. Cotton, and L. Margerin (2006), Nonstationary stochastic simulation of strong ground motion time histories including natural variability: Application to the k-net Japanese database, Bull. Seismol. Soc. Am., 96(6), 2103-2117.

Rousseau, N. (1999), Study of seismic signal associated with rockfalls at 2 sites on the Réunion island (Indian Ocean): Mahavel cascade and Soufrière cavity, PhD thesis, Université de Paris, Paris.

Schneider, D., P. Bartelt, J. Caplan-Auerbach, M. Christen, C. Huggel, and B. W. McArdell (2010), Insights into rock-ice avalanche dynamics by combined analysis of seismic recordings and a numerical avalanche model, J. Geophys. Res., 115, F04026, doi:10.1029/2010JF001734.

Sethian, J. A. (1996), A fast marching level set method for monotonically advancing fronts, Proc. Natl. Acad. Sci., 93(4), 1591 - 1595.

Singer, K. N., W. B. McKinnon, P. M. Schenk, and J. M. Moore (2012), Massive ice avalanches on lapetus mobilized by friction reduction during flash heating, Nat. Geosci., 5(8), 574-578.

Singh, S., and M. Ordaz (1994), Seismic energy release in Mexican subduction zone earthquakes, Bull. Seismol. Soc. Am., 84(5), $1533-1550$.

Smart, K., D. Hooper, and D. Sims (2010), Discrete Element Modeling of Landslides in Valles Marineris, Mars, AGU, San Francisco, Calif., 13-17 Dec.

Sparks, R., and S. Young (2002), The eruption of Soufrière Hills Volcano, Montserrat (1995-1999): Overview of scientific results, in The Eruption of Soufrière Hills Volcano, Montserrat, From 1995-1999, vol. 21, edited by T. H. Druitt and B. P. Kokelaar, pp. 45-69, Geol. Soc. Mem., London.

Suriñach, E., et al. (2005), Seismic detection and characterization of landslides and other mass movements, Nat. Hazards Earth Syst. Sci., 5(6), $791-798$.

Trifunac, M. D., and A. G. Brady (1975), A study on the duration of strong earthquake ground motion, Bull. Seismol. Soc. Am., 65(3), 581-626.

Trofimovs, J., et al. (2006), Submarine pyroclastic deposits formed at the Soufrière Hills Volcano, Montserrat (1995-2003): What happens when pyroclastic flows enter the ocean?, Geology, 34(7), 549-552.

Tsutsumi, A., and T. Shimamoto (1997), High-velocity frictional properties of gabbro, Geophys. Res. Lett., 24(6), 699-702.

Vilajosana, I., E. Surinach, A. Abellan, G. Khazaradze, D. Garcia, and J. Llosa (2008), Rockfall induced seismic signals: Case study in Montserrat, Catalonia, Nat. Hazards Earth Syst. Sci., 8(4), 805-812.

Voight, B., et al. (2002), The 26 December (boxing day) 1997 sector collapse and debris avalanche at Soufrière Hills Volcano, Montserrat, 21 , $363-408$

Yamada, M., H. Kumagai, Y. Matsushi, and T. Matsuzawa (2013), Dynamic landslide processes revealed by broadband seismic records, Geophys. Res. Lett., 40, 2998-3002, doi:10.1002/grl.50437.

Young, S. R., R. S. J. Sparks, W. P. Aspinall, L. L. Lynch, A. D. Miller, R. E. Robertson, and J. B. Shepherd (1998), Overview of the eruption of Soufriere Hills Volcano, Montserrat, 18 July 1995 to December 1997, Geophys. Res. Lett., 25(18), 3389-3392.

Zhao, J., et al. (2012), Model space exploration for determining landslide source history from long-period seismic data, Pure Appl. Geophys., $172,389-413$. 